This item was submitted to Loughborough's Research Repository by the author.

Items in Figshare are protected by copyright, with all rights reserved, unless otherwise indicated.

\title{
Aggregate dividends and consumption smoothing
}

PLEASE CITE THE PUBLISHED VERSION

http://dx.doi.org/10.1016/j.irfa.2015.08.008

PUBLISHER

(C) Elsevier

VERSION

AM (Accepted Manuscript)

PUBLISHER STATEMENT

This work is made available according to the conditions of the Creative Commons Attribution-NonCommercialNoDerivatives 4.0 International (CC BY-NC-ND 4.0) licence. Full details of this licence are available at: https://creativecommons.org/licenses/by-nc-nd/4.0/

\section{LICENCE}

CC BY-NC-ND 4.0

\section{REPOSITORY RECORD}

Huang-Meier, Winifred, and Mark Freeman. 2019. "Aggregate Dividends and Consumption Smoothing". figshare. https://hdl.handle.net/2134/18797. 


\title{
Aggregate Dividends and Consumption Smoothing
}

\author{
Winifred Huang-Meier ${ }^{\mathrm{a}}$, Mark C. Freeman ${ }^{\mathrm{b}}$ \\ ${ }^{a}$ Aston Business School, Aston University, Birmingham B4 7ET, United Kingdom \\ ${ }^{\mathrm{b}}$ School of Business and Economics, Loughborough University, Leicestershire LE11 3TU, \\ United Kingdom
}

\begin{abstract}
We show that net equity payouts from the corporate sector play a crucial role in helping individuals manage their consumption path across the business cycle. In particular, we show that, as investors' desire to smooth consumption increases, optimal aggregate dividends become both more volatile and more counter-cyclical to help counterbalance pro-cyclical labor income. These findings are robust to whether or not agency conflicts exist in the economy.
\end{abstract}

JEL classification codes: E13, E21, G35

Keywords: Aggregate dividend policy, Consumption smoothing, Habit formation, Dynamic stochastic general equilibrium models 


\section{Introduction}

There is a disconnection between microeconomic and macroeconomic models of optimal dividend policy. In the corporate finance literature, equity payout behavior at the individual firm level is either considered irrelevant (Miller and Modigliani, 1961) or depends on a range of company-specific issues including, inter alia, taxation, signalling and agency conflicts. ${ }^{1}$ By contrast, in dynamic stochastic general equilibrium (DSGE) models, when the consumption requirement of the representative investor is modelled alongside the optimization problem of the corporate sector, an optimal aggregate dividend policy is frequently found to exist.

In many settings, standard DSGE models predict that equity payout behavior at the portfolio level should be highly counter-cyclical; see, for example, the discussions in Liu and Miao (2015), Hirshleifer et al. (2015) and Huang-Meier et al. (2015). This is because, when economic times are good, companies have excellent investment opportunities and therefore wish to retain cash for new projects. Simultaneously, individuals have little requirement for additional revenue as their labor income is highly pro-cyclical. The low demand from households for income from financial assets, and the high demand for new investment from corporations, leads to predicted low dividend payments in economic booms.

This theoretical prediction, though, clearly conflicts with observed financial market behavior. Jermann and Quadrini (2012) report a correlation of $+41 \%$ between gross equity payouts and GDP while Huang-Meier et al. (2015) report a correlation of $+50 \%$ between real aggregate dividends changes and real GDP growth. Even net dividends, which comprise of gross dividends minus new equity issue and share repurchases, are not highly countercyclical in the manner that is predicted by most DSGE models. ${ }^{2}$

To overcome this anomaly, a number of papers force the pro-cyclicality of equity payouts onto their economies by modelling dividends as a levered claim to consumption; see, for example, Bansal and Yaron (2004), Ju and Miao (2012) and Liu and Miao (2015). But this does little to explain the underlying reason for this relationship. Both Hirshleifer et al.

\footnotetext{
${ }^{1}$ Dividend policy work in the corporate finance literature has incorporated different corporate accounting and finance issues, such as taxation (Brennan, 1970; Miller and Scholes, 1978; Poterba and Summers, 1985; and Harris et al., 2001), dividend clientele effects (Pettit, 1977), agency conflicts (Jensen and Meckling, 1976; Easterbrook, 1984; Jensen, 1986; and La Porta et al., 2000), asymmetric information and signalling (Miller and Rock, 1985; DeAngelo et al., 1996; Benartzi et al., 1997; Dong et al., 2005; and Fuller and Goldstein, 2011), and the bird-in-the-hand fallacy (Bhattacharya, 1979). For reviews of firm-level payout policy, see, for example, Allen and Michaely (2003), Brav et al. (2005), and Ben-David (2010).

${ }^{2}$ For instance, Covas and Den Haan (2011) find the correlation between net dividend payments and GDP to be in the range of $-33 \%$ and $+54 \%$ depending on the firm size. In this paper, we report a correlation of $-20 \%$ between net aggregate equity payouts and GDP.
} 
(2015) and Huang-Meier et al. (2015), by contrast, make dividends more pro-cyclical endogenously by incorporating capital adjustment costs into their economic models. This makes firms less willing to retain capital in good times, thus releasing more money for distribution amongst shareholders. Huang-Meier et al. (2015), following Carceles-Poveda (2005, 2009), also endogenize pro-cyclical dividends through a model with agency conflicts, where managers' own reward function makes them averse to volatility in dividend payments. Other approaches have also been suggested. Liu and Miao (2015) argue that incorporating leverage allows firms to raise capital in strong conditions through debt, reducing the need to cut dividends at such times. Hirshleifer et al. (2015) note that the combined effect of extrapolation bias, capital adjustment costs, and recursive preference incorporated into the modelled economy may potentially help to reconcile consumption and dividend behavior.

These explanations, though, all focus on the production side of the economy, with little consideration given as to how investor preferences might affect the relationship between the business cycle and the payout policy of firms. Since the predicted strong countercyclicality of dividend payments in standard DSGE models emerges as much from the low marginal utility of consumption in strong economic conditions as it does from better investment opportunities for the corporate sector, this is an important gap in the literature that we attempt to fill here. Our study, therefore, follows closely in the spirit of Marsh and Merton's (1987, p. 4-5) observation that: 'In a purely demand-driven model for dividends, the demand for dividends is not firm-specific because investors only care about the dividendcapital gain mix at the aggregate level... Thus equilibrium aggregate dividends may be determinate, but which firms service this demand and the quantity that each chooses to supply may not.'

Within our model, the representative household derives income for consumption from three sources; salary, changes in the level of lending provided to firms alongside the associated interest payments made on existing corporate debt, and cash payouts to equity. To capture the desire of the household to smooth consumption over time, we concentrate on internal habit formation utility functions. As has been widely documented elsewhere (e.g., Constantinides, 1990), we find that, as the habit motive strengthens, the optimal consumption path becomes less volatile. More importantly, our study documents that this effect is not driven equally by all three components of income. For example, if we incorporate agency conflicts into our model, investors' income from debt is (approximately) uncorrelated with output for all levels of habit formation. Changes in lending practice, therefore, are not used by investors as a mechanism to aid in consumption smoothing. Furthermore, in a world with 
no agency conflicts, labor income becomes both more pro-cyclical and more volatile as the habit motive rises; a result that is counterintuitive.

By contrast, we demonstrate that dividend payments at the portfolio level play a vital role in helping individuals to manage their consumption paths across the business cycle, with optimal aggregate equity payout behavior being highly sensitive to the strength of investors' desire to smooth consumption over time. This result holds both in the presence and absence of agency conflicts. This is our central contribution.

The paper proceeds as follows. In Section 2, we present our baseline theoretical model, which excludes agency conflicts. We describe the optimization problems of the representative household and the firms within the economy. We also describe how bankruptcy can occur within our framework and the impact this has on the corporate borrowing rate. After deriving the equilibrium and describing both the market clearing conditions and our choice of parameter values, we present our main results. These clearly show the sensitivity of optimal aggregate dividend policy to investor preferences, and illustrate the way in which aggregate equity payouts play a vital role in helping investors to smooth consumption. In Section 3, we turn to a model where managers maximize their own utility function rather than that of their shareholders. Our central findings are largely unchanged from the baseline model. Section 4 compares the implications of our models with the observed behavior of the US economy. This supports our theoretical results that the cyclical variations in dividend behavior, consumption behavior and labor income are correlated. Section 5 provides some concluding comments.

\section{The value-maximizing model (VM)}

In this section we describe our main DSGE model, which is an extension of earlier seminal work by Kydland and Prescott (1982), Hansen (1985), and others. Our paper lies within the stream of theoretical studies that explicitly incorporate equity payouts for the representative firm. While this has been a feature in a number of previous studies, this is either often not the central focus of their work (for example, Baxter et al., 1998; Alessandrini, 2003), or the point of interest differs significantly from the purpose of this study (for example, Levy and Hennessy, 2007; Covas and Den Haan, 2011; Jermann and Quadrini, 2012).

The most closely related previous studies to this are those by Carceles-Poveda (2009), Liu and Miao (2015), Hirshleifer et al. (2015), and Huang-Meier et al. (2015). CarcelesPoveda (2009) considers risk-averse firms in the DSGE model and shows that this feature 
contributes to the explanation of the behavior of stock returns and macroeconomic aggregates in incomplete markets. Liu and Miao (2015) study the effect of the investor's generalized disappointment aversion preferences on equity returns when the production economy is set to include leverage with a pro-cyclical dividend process. Hirshleifer et al. (2015) explain stylized facts about business cycles by using a DSGE model with recursive preferences when considering that individuals are likely to overextrapolate future performance from past performance of a small sample. Huang-Meier et al. (2015) focus on the pro-cyclical behavior of gross dividend payouts when low elasticity of investment is endogenized. The authors find that the role of agency conflicts in the real business cycle models is important as it explains pro-cyclical dividend payout behavior better than the presence of capital adjustment costs.

\section{1 The economic environment}

We assume that there are a large number of firms that all experience the same technology shocks as well as idiosyncratic capital shocks, one representative household and one representative bank. Equilibrium is reached when each is simultaneously able to maximize its individual objective function subject to budget and market clearing constraints.

\subsubsection{The household's problem}

The representative household's preferences are captured by a time-inseparable utility function that includes consumption and leisure:

$$
\sum_{h=0}^{\infty} \beta^{h} u\left(c_{t+h}, c_{t+h-1}, 1-l_{t+h}^{s}\right)
$$

where $\beta$ is the subjective discount factor, $u(\cdot)$ is the period utility function for consumption and leisure, $c_{t+h}$ is the level of consumption at time $t+h, l^{s}$ is the number of hours worked in the labor market and the total number of hours available is normalized to one. The $s$ superscript here refers to the fact that this is the supply of labor, which is to be distinguished from the firm's demand for labor, $l^{d}$. This results in $1-\mathrm{l}_{t+h}^{s}$ being available for leisure at time $t+h$. That the utility function for time $t+h$ includes consumption at time $t+h-1$ reflects internal habit formation. While this preference characteristic has featured in a number of previous DSGE models (see, for example, Constantinides, 1990; Carroll, 2000; Boldrin et al., 2001; Seckin, 2001; Otrok et al., 2002; Gershun, 2010), these earlier studies do not consider optimal aggregate dividend policy, which is our focus here. 
In order to maximize its expected lifetime utility, at $t$ the household can choose the current level of consumption and the amount of labor that it agrees to supply to the corporate sector. In addition, there are capital markets that allow the household to adjust its consumption profile across time. In particular, it can purchase $n_{t}$ shares in an aggregate of firms and hold $b_{t}^{H}$ in a risk-free bank deposit account over the interval $[t, t+1]$. The representative agent's optimization problem at time $t$ therefore becomes:

$$
\max _{c_{t}, l_{t}^{s}, n_{t}, b_{t}^{H}} \sum_{h=0}^{\infty} \beta^{h} u\left(c_{t+h}, c_{t+h-1}, 1-l_{t+h}^{s}\right)
$$

subject to the budget constraint

$$
c_{t}+q_{t} n_{t+1}+b_{t}^{H} \leq w_{t} l_{t}^{s}+\left(q_{t}+d_{t}\right) n_{t}+R_{f t-1} b_{t-1}^{H}
$$

where $q_{t}$ is the share price of the representative firm at time $t, n_{t}$ is the number of shares held by the representative investor at time $t, w_{t}$ is the wage rate for labor, and $d_{t}$ denotes the dividends paid by firms. $R_{f t-1}$ represents the gross risk-free rate for the period $[t-1, t]$, which is determined endogenously (details in the Appendix 1). We denote the labor salary by $s_{t}=w_{t} l_{t}^{s}$

The habit formation utility function that we use throughout this paper is:

$$
u\left(c_{t}, c_{t-1}, 1-l_{t}\right)=\frac{\left[\left(c_{t}-\xi c_{t-1}\right)^{\rho}\left(1-l_{t}\right)^{1-\rho}\right]^{1-\gamma}}{1-\gamma}
$$

The household utility is determined by the multiplied effect of consumption and leisure, where $\rho$ captures the relative weight placed on consumption against leisure. $\xi$ captures the strength of habits for household consumption and $\gamma$ is the coefficient of relative risk aversion. The multiplicative functional form for habit formation is commonly used in DSGE modelling; see Campbell (1994) and Dennis (2009) for consumption habits in a real business cycle model and in a New Keynesian business cycle model respectively.

We restrict our analysis to internal habit formation with respect to single-period lagged consumption. This is for two reasons. First, and most importantly, it simplifies the exposition. Second, Fuhrer (2000) empirically tests persistence in the internal habitformation reference level and found that the habit stock prior to time $t-1$ has little influence on overall utility. We conjecture that our results would, though, extend beyond this simple 
framework. This is because both internal habit models with longer lagged reference periods (Constantinides, 1990; Fuhrer, 2000) and "Keeping up with the Joneses" external habit models (Campbell and Cochrane, 1999; Lettau and Uhlig, 2000) lead to smoother optimal consumption paths than the no-habit case. Since habit formation is used within this framework as a mechanism for adjusting the investor's desire to smooth consumption, similar effects could be generated from a wide range of habit formation models. Investigating the precise empirical effects of different specifications would be a fruitful area for future research.

\subsubsection{The production sector in a frictionless economy}

The economy that we consider consists of a large number $N$ of individual firms. These experience an identical technology shock each period as well as an idiosyncratic shock to their capital and earnings base. In conjunction with corporate borrowing, the idiosyncratic shocks can lead to bankruptcy at the individual firm level but not at the aggregate level. In this subsection, we consider the behavior of the economy in the absence of idiosyncratic shocks, which are then introduced below. This simplification allows us to begin to model the economy as if there were a single representative firm, denoted by a superscript $r$.

The output, $y_{t}^{r}$ of the representative firm at time $t$ is given by a constant returns-toscale Cobb-Douglas production function:

$$
y_{t}^{r}=\left(k_{t-1}^{r}\right)^{\alpha}\left(z_{t} l_{t}^{d}\right)^{1-\alpha}
$$

where $k_{t}^{r}, l_{t}^{d}$ and $z_{t}$ denote the capital employed by the firm, the labor employed by the firm and a labor augmenting technological shock respectively, while $\alpha$ is the output elasticity of capital. The technical change is assumed to follow a first order autoregressive process in logs:

$$
\log z_{t}=\psi \log z_{t-1}+\epsilon_{t}
$$

where $\psi$ is the parameter of persistence and $\epsilon_{t}$ is an independently and identically normally distributed random variable; $\epsilon_{t} \sim N\left(0, \sigma_{\epsilon}^{2}\right)$. The capital base of the representative firm evolves according to:

$$
k_{t}^{r}=i_{t}^{r}+(1-\eta) k_{t-1}^{r}, \quad 0<\eta<1
$$

where $i_{t}^{r}$ represents net investment by the firm at time $t$ and $\eta$ denotes the fixed capital depreciation rate. In addition to equity, the firm can augment its capital base by borrowing an 
amount $b_{t-1}$ for the interval $[t-1, t]$ at a gross corporate interest rate $R_{t-1} \geq R_{f t-1}{ }^{3}$ It is assumed that the firm pays corporation tax at a fixed rate $\tau$ and that the interest payment at time $t,\left(R_{t-1}-1\right) b_{t-1}$, is tax-deductible. Therefore, the free cash flow of the firm before accounting for investments is given by:

$$
\pi_{t}^{r}=(1-\tau)\left(y_{t}^{r}-w_{t} l_{t}^{d}-\left(R_{t-1}-1\right) b_{t-1}\right)
$$

Net investment in the firm, $i_{t}$, is generated from this 'profit', $\pi_{t}^{r}$, the net cash flow from paying off last period's debt and re-borrowing this period, $b_{t}-b_{t-1}$, minus any dividend paid, $d_{t}^{r}$. This results in:

$$
\begin{aligned}
i_{t}^{r} & =(1-\tau)\left(y_{t}^{r}-w_{t} l_{t}^{d}-\left(R_{t-1}-1\right) b_{t-1}\right)+b_{t}-b_{t-1}-d_{t}^{r} \\
\Rightarrow d_{t}^{r} & =(1-\tau)\left(y_{t}^{r}-w_{t} l_{t}^{d}-R_{t-1} b_{t-1}\right)-\tau b_{t-1}+b_{t}-i_{t}^{r}
\end{aligned}
$$

It is important to stress that dividends are not a 'residual' within this framework. While standard accounting equalities between gross dividends, free cash flow, investment, capital structure choices, and net new capital inflows apply, the general equilibrium setting means that these variables are determined simultaneously. That there are both corporate taxes and bankruptcy frictions (see below) leads, in the manner of Modigliani and Miller (1963), to an optimal capital structure while the investment levels of firms are jointly determined by the corporate opportunities available and investors' desire for the income stream provided by dividends.

\subsubsection{The presence of bankruptcy}

In addition to the aggregate labor-augmenting technology shock, each firm experiences an individual shock. We define the earnings before interest and tax for the representative firm as $E B I T_{t}^{r}=y_{t}^{r}-w_{t} l_{t}^{d}$. Each of the $N$ individual firms then experiences a firm-specific idiosyncratic shock to its earnings and capital base. For firm $n$ at time $t, E B I T_{n t}=$ $\delta_{n t} E B I T_{t}^{r}$ and $k_{n t}=\delta_{n t} k_{t}^{r}$, where $\delta_{n t}$ is an independent drawing from the probability density function $f(\delta)$ supported on the strictly positive real line $\mathfrak{R}^{+}$. This differs from the financial shock in Jermann and Quadrini (2012) which is identical across firms. The consequence of this is that any individual firm will not be able to pay off its debt if $\delta_{n t+1}\left[E B I T_{t+1}^{r}+(1-\eta) k_{t}^{r}\right]<R_{t} b_{t}$. This bankruptcy condition for firm $n$ can be re-written as $\delta_{n t+1}<x_{t+1}$ where

\footnotetext{
${ }^{3}$ Since the theoretical setting of our paper allows for a mixed debt-and-equity funding structure for the firm, this study is also loosely related to the body of work that considers capital structure choices across business cycles. This has been considered by, amongst others, Levy and Hennessy (2007), Covas and Den Haan (2011) and Jermann and Quadrini (2012).
} 


$$
x_{t+1}=\frac{b_{t} R_{t}}{E B I T_{t+1}^{r}+(1-\eta) k_{t}^{r}}
$$

As the overall number of firms in the economy is large, the proportion of firms in bankruptcy, $\Gamma_{t}$, is given by

$$
\Gamma_{t}=\int_{0}^{x_{t}} f(\delta) d \delta
$$

To operationalize this setting, we set $f(\delta)$ to be a rectangular distribution on the interval $[U, L]:$

$$
f(\delta) \begin{cases}0 & 0<\delta<L \text { and } U<\delta<\infty \\ \frac{1}{U-L} & \delta \in[L, U]\end{cases}
$$

resulting in $\Gamma_{t}=\left(x_{t}-L\right) /(U-L)$.

This risk of bankruptcy introduces several frictions into the economy. First, we assume that aggregate investment, dividends and new capital within the economy are all reduced on a pro-rata basis with the proportion of firms who become bankrupt when compared to the representative firm case: $i_{t}=\left(1-\Gamma_{t}\right) i_{t}^{r}, d_{t}=\left(1-\Gamma_{t}\right) d_{t}^{r}$, and $k_{t}=$ $\left(1-\Gamma_{t}\right) k_{t}^{r}$. In addition, we assume that aggregate output is reduced by earnings adjusted for both the proportion of firms who go bankrupt and the monetary recovery rate $\theta$ from bankruptcy:

$$
y_{t}=y_{t}^{r}-(1-\theta) \Gamma_{t} E B I T_{t}^{r}
$$

In light of these frictions, the objective of the firms' managers in this baseline model is to maximize shareholder wealth, or equivalently the expected present value of future dividend payments. They have three control variables to enable them to do this; labor, capital employed and how much borrowing is raised: $l_{t}^{d}, k_{t}, b_{t}$. Let $M_{t, h}$ denote the stochastic discount factor of the representative household at time $t$ for horizon $h$. The optimization problem then facing the firms' managers is:

$$
\max _{l_{t}^{d}, k_{t}, b_{t}} d_{t}+E_{t}\left[\sum_{h=1}^{\infty} M_{t, h} d_{t+h}\right]
$$

\subsubsection{The banking sector}

The final impact of bankruptcy on our economy is that it influences the corporate bond premium, $R_{t}-R_{f t}$. There is a neutral banking sector that balances the savings of the representative household with the borrowing demands of the $N$ individual firms. Since there 
are a large number of companies, the bank can construct a well-diversified portfolio of the debt of the aggregate of firms. While this is subject to the labor-augmenting technology shock, the proportion of firms going bankrupt is known with certainty each period and therefore the cash flows to the bank are non-stochastic. As a consequence, it only requires the risk-free rate of return on its overall aggregate portfolio of holdings.

For the portion of the firms that do not go bankrupt, $1-\Gamma_{t}$, the bank fully recovers all the capital that it is owed, $b_{t} R_{t}$. For the bankrupt firms, the bank experiences different frictions to the overall economy by losing a proportion $1-\theta$ of the money that is available for recovery. The relationship between $R_{t}$ and $R_{f t}$ is then given by:

$$
b_{t} R_{t}\left(1-\Gamma_{t}\right)+\theta\left(E B I T_{t+1}^{r}+(1-\eta) k_{t}\right) \int_{0}^{x_{t+1}} \delta f(\delta) d \delta=b_{t} R_{f t}
$$

By substituting the rectangular probability distribution function $f(\delta)$ into eq. (15), the bank can set the corporate interest rate, conditional on knowing the level of debt and the risk-free interest rate, through the relationship:

$$
R_{t}=\left\{b_{t} R_{f t}-\frac{\theta}{2(U-L)}\left[E B I T_{t+1}^{\gamma}+(1-\eta) k_{t}\right]\left[x_{t+1}^{2}-L^{2}\right]\right\} \frac{U-L}{b_{t}\left(U-x_{t+1}\right)}
$$

Based on the calibrations described below, the optimal debt/equity mix in our economy appears realistic; the steady state leverage value of $b_{t} /\left(b_{t}+q_{t}\right)=38 \%$. This leads to very low bankruptcy risk and so $R_{t}-1$ is very close to $R_{f t}-1$, with steady state values of $1.07 \%$ and $1.01 \%$ respectively.

\subsubsection{Determining the equilibrium}

To determine the dynamic stochastic general equilibrium, we solve the firms' and the household's optimization problems; eqs (2) and (14). We show in Appendix 1 that this results in five equilibrium conditions:

$$
\begin{gathered}
(1-\alpha) \frac{y_{t}}{l_{t}}=-\frac{\frac{\partial u\left(c_{t}, c_{t-1}, 1-l_{t}^{s}\right)}{\partial l_{t}^{s}}}{\frac{\partial u\left(c_{t}, c_{t-1}, 1-l_{t}^{S}\right)}{\partial c_{t}}+\beta \frac{\partial u\left(c_{t+1}, c_{t}, 1-l_{t+1}^{s}\right)}{\partial c_{t}}} \\
1=E_{t}\left[M_{t, 1} R_{f t}\right] \\
R_{f t}=(1-\tau) \alpha k_{t}^{\alpha-1}\left(z_{t+1} l_{t+1}\right)^{1-\alpha}+1-\eta \\
R_{t}=\left(\frac{1}{1-\tau}\right)\left[R_{f t}-\tau\right]
\end{gathered}
$$




$$
q_{t}=E_{t}\left[M_{t, 1}\left(q_{t+1}+d_{t+1}\right)\right]
$$

From the banking sector, we have another two conditions (eqs (10) and (16)).

The next step is to obtain market clearing conditions. This economy begins with a capital stock $k_{t}>0$ and an initial level of the productivity shock $z_{t}>0$. In equilibrium, consumption, capital, and labor need to be determined simultaneously. For the market to clear, four conditions must hold: aggregate borrowing must equal aggregate lending, $b_{t}^{H}=b_{t}$, the equity market must clear, $n_{t}=1$, the labor market must clear, $l_{t}^{d}=l_{t}^{s}=l_{t}$, and the goods market must clear, $y_{t}=i_{t}+c_{t}$.

\subsection{Calibration}

Most values we used for our parameters are standard and borrowed from Alessandrini (2003); see Table 1. The constant capital share in a Cobb-Douglas production function, $\alpha$, is set to 0.35 . The quarterly capital depreciation rate, $\eta$, is 0.019 . The quarterly intertemporal subjective time discount factor $\beta$ is set to 0.99 . The persistence of the idiosyncratic technology shock, $\psi$, is given a value of 0.95 . The standard deviation of the idiosyncratic shock is assumed to be 0.00712 . The recovery rate, $\theta$, and tax rate, $\tau$, are assigned values of 0.92 and $6 \%$ respectively.

\section{[Table 1]}

We select values for $U$ and $L$ of 1.225 and 0.475 . In the momentary utility function, we set $\rho=0.36$ following Campbell (1994). ${ }^{4}$ The coefficient of relative risk aversion for the representative investor's utility function, $\gamma$, is set to 2 . The habit persistence level, $\xi$, ranges from 0 to 0.8 .

\subsection{Results}

Our results for the value-maximizing economy are reported in Tables 2 and 3. The former presents a summary of the mean and the relative standard deviations (RSD) of each macroeconomic variable. ${ }^{5}$ The latter presents the correlation of different macroeconomic variables with consumption, dividend and output.

[Table 2]

[Table 3]

\footnotetext{
${ }^{4}$ Campbell (1994) sets a value of labor as 0.33 and then obtains the value of the fraction of time devoted to market activities. Our model shows a steady state value of labor as $0.32(\xi=0)$ and $0.33(\xi=0.8)$.

${ }^{5}$ Relative standard deviation is each variable's standard deviations divided by its mean value. It is also known as the 'coefficient of variation'.
} 
Panel A of Table 2 shows the estimated steady-state first moment of each variable. This simulation confirms that the no-trend optimal aggregate dividends are positive and insensitive to the level of habit persistence $(\xi)$. The ratio of the aggregate dividends to salary $(d / s)$ is $0.0102(=0.09 / 8.84)$ meaning that investors get $99 \%$ of their income from salary and $1 \%$ from dividends. The aggregate dividends-consumption ratio $(d / c)$ is 0.0989 $(=0.09 / 0.91)$ implying that dividends contribute $10 \%$ of investors' consumption. It is also worth noting that the consumption - salary ratio $(c / s)$ is $0.1029(=0.91 / 8.84)$, indicating ten per cent of salary goes to investors' consumption.

As the level of habit persistence $(\xi)$ increases from 0 to 0.8 , the RSD of aggregate consumption in Panel B of Table 2 declines from 0.30 to 0.21 . That consumption growth becomes smoother with increased habit motive is consistent with previous research (see, e.g., Constantinides, 1990) and this is the central feature that we capture by incorporating habit formation utility into our economy. In addition, the pro-cyclicality of consumption, $\operatorname{corr}\left(y_{t}, c_{t}\right)$ reported in Table 3 , becomes less pronounced as the habit motive increases.

How is this consumption smoothing brought about? Consumption comes from three sources; salary, dividend payments and changes in holding of the risk-free asset after interest has been paid. Salaries, which are positively correlated with output in all cases because both the wage rate rises $\left(\operatorname{corr}\left(y_{t}, w_{t}\right)>0\right)$ and people work longer hours $\left(\operatorname{corr}\left(y_{t}, l_{t}\right)>0\right)$ in benign economic conditions, become both more volatile and more pro-cyclical as the habit motive gets stronger. As $\xi$ increases from 0 to 0.8 , the relative standard deviation of $s_{t}$ increases from 3.17 to 4.03 while $\operatorname{corr}\left(y_{t}, s_{t}\right)$ rises from 0.84 to 0.90 . Therefore, somewhat counter-intuitively, salary effects magnify both the volatility and pro-cyclicality of consumption growth as the habit motive increases. The observed increased level of consumption smoothing with higher $\xi$ must then be driven instead by cash flows associated with financial assets. Consistent with this, bond holding is pro-cyclical in all cases, so consumption is smoothed to some extent by increasing (decreasing) lending in good (bad) economic conditions. As $\xi$ increases from 0 to $0.8, \operatorname{corr}\left(y_{t}, b_{t}\right)$ rises from 0.37 to 0.44 and the relative standard deviation of bond holdings increases from 0.19 to 0.22 . This does reduce the volatility and pro-cyclicality of consumption as expected.

In addition, optimal dividend behavior is highly sensitive to the assumed level of habit formation. As $\xi$ increases from 0 to 0.8 , so the RSD of dividends increases from 2.44 to 3.21 and the payments become more counter-cyclical; $\operatorname{corr}\left(y_{t}, d_{t}\right)$ increases in absolute terms from 0.71 to 0.85 . This is clearly significantly impacting upon the ability of the 
representative agent to smooth consumption. This is further illustrated by Fig. 1, where the ratio $\sigma_{d} / \sigma_{c}$ for values of $\xi \in\{0, \ldots, 0.8\}$ is plotted.

\section{[Figure 1]}

This figure shows that, in aggregate, the relative standard deviation of dividends to consumption rises dramatically as the habit motive becomes large. Counter-cyclical dividends are offsetting pro-cyclical salary to reduce the consumption volatility of the representative investor.

An alternate way of illustrating this effect is by examining the correlations of consumption with its three individual sources. In all cases, consumption is positively correlated with salary but negatively correlated with the cash flows from risk-free investment and the equity market. ${ }^{6}$ However, as the habit motive becomes more intense, the strong positive relation with salary becomes noticeably weaker. By reducing the reliance of consumption on salary, dividends help reduce both consumption's volatility and procyclicality.

Figs 2 and 3 respectively illustrate the impulse responses of the expected future path of aggregate dividends and consumption in two cases, without habit formation $(\xi=0)$ and with strong habit formation $(\xi=0.8)$. These response functions further indicate that consumption growth is smoother when habit persistence is higher. Consumption with the highest habit motive of $\xi=0.8$ has low deviations (far below 0.001) in the first few quarters after the shock. This contrasts with the no-habit motive case, $\xi=0$, when the deviation is higher than 0.002 . The figures further show that aggregate dividends fluctuate more in the habit formation case than in the no-habit formation case. Notice, for example, that the first ten quarters' deviation from the steady state after the shock is between $-1 \times 10^{-3}$ and $-2 \times 10^{-3}$ for the no-habit-motive-investor economy, yet is higher than $-2 \times 10^{-3}$ for the with-high-habit-motive-investor economy.

[Figure 2]

[Figure 3]

Aggregate investment, $i_{t}$, has similar characteristics to $d_{t}$ both with and without habit, in terms of its volatility and the absolute levels of its correlations with consumption and income. In particular, the optimal investment path becomes more volatile as the habit motive

\footnotetext{
${ }^{6}$ Remember that $b_{t}$ is the level of bank lending. So, if $\operatorname{corr}\left(c_{t}, b_{t}\right)$ is positive, then there is a negative correlation between cash taken from the risk-free asset and the level of economic activity.
} 
increases and investment volatility is close to aggregate payout volatility in each of the different habit persistence cases. As investors' habit motive gets stronger, firms must adapt their own investment plans to ensure that they help maximize the expected utility of the agent. The correlation between investment and consumption also decreases as the latter is smoothed, which is consistent with the absolute relationship between dividends and consumption. Investment is nearly perfectly correlated with output for all values of $\xi$ because of the high persistence of technology change; $\psi=0.95$. High output this year signals high future profitability, giving firms a strong incentive to increase investment levels.

In this general equilibrium setting, the habit motive of investors is shown to have a significant influence not only on investors' labor and consumption decisions but also on the investment, financing and payout policy of the firm. This suggests that there is a significant interaction between corporate policy and investor utility. However, there is one implication of this model that appears to be at odds with the observed empirical data. In this baseline case, dividends are predicted to be highly counter-cyclical in each calibration. As we discussed in the introduction, this is a feature common of many DSGE studies and makes dividends a highly suitable control variable for smoothing investor consumption across the business cycle. However, this finding is inconsistent with observed cyclicality of both gross and net aggregate payout behavior.

To overcome this anomaly, we follow an approach employed by both CarcelesPoveda (2009) and Huang-Meier et al. (2015), which is to introduce agency conflicts into the model. This has similar implications for dividend behavior to economies with capital adjustment costs, but Huang-Meier et al. (2015) argue that agency models better explain observed market behavior. The results in these studies are also qualitatively comparable to those of Jermann and Quadrini (2012) who have suggested a relatively complex DSGE model with both frictions and shocks.

\section{Risk-averse firms (RA)}

Following Radner (1970), Sandmo (1971) and Leland (1972), in this section we assume that the firms' managers maximize their own utility function rather than working in their shareholders' best interests. In this risk-averse firms model (RA), managers have risk-averse utility with respect to future dividends $\left(d_{t}\right)$ and thus optimize: 


$$
\max _{l_{t}^{d}, k_{t}, b_{t}} E_{t}\left[\sum_{h=1}^{\infty} \phi^{h} \frac{d_{t+h}^{1-\gamma_{F}}-1}{1-\gamma_{F}}\right]
$$

where $\gamma_{F}$ is the coefficient of relative risk aversion of the manager and $\phi$ denotes the manager's time discount factor. Carceles-Poveda $(2005,2009)$ contend that this risk-aversion assumption improves our understanding of managers' behavior. Huang-Meier et al. (2015) also show that such models significantly change the optimal correlation between dividends and output. We extend their findings here to a mixed equity and debt environment in the presence of habit formation.

We show in Appendix 3 that solving the household and the firm's optimization problem (eqs (2) and (31)) gives a set of five equilibrium conditions for the RA case:

$$
\begin{gathered}
(1-\alpha) \frac{y_{t}}{l_{t}}=-\frac{\frac{\partial u\left(c_{t}, c_{t-1}, 1-l_{t}^{s}\right)}{\partial l_{t}^{s}}}{\frac{\partial u\left(c_{t}, c_{t-1}, 1-l_{t}^{s}\right)}{\partial c_{t}}+\beta \frac{\partial u\left(c_{t+1}, c_{t}, 1-l_{t+1}^{s}\right)}{\partial c_{t}}} \\
1=\phi E_{t}\left[\left(\frac{d_{t}}{d_{t+1}}\right)^{\gamma_{F}} R_{f t}\right] \\
R_{f t}=(1-\tau) \alpha k_{t}^{\alpha-1}\left(z_{t+1} l_{t+1}\right)^{1-\alpha}+1-\eta \\
R_{f t}=(1-\tau) R_{t}+\tau \Rightarrow R_{t}=\left(\frac{1}{1-\tau}\right)\left[R_{f t}-\tau\right] \\
q_{t}=E_{t}\left[M_{t, 1}\left(q_{t+1}+d_{t+1}\right)\right]
\end{gathered}
$$

In equilibrium, the above eqs (23) to (27) must hold together with the bank sector (eqs (10) and (16)) and market clearing conditions $\left(b_{t}^{H}=b_{t}, n_{t}=1, l_{t}^{d}=l_{t}^{s}=l_{t}\right.$, and $\left.y_{t}=i_{t}+c_{t}\right)$.

To calibrate the RA model, we set $\phi$ equal to 0.99 and $\gamma_{F}$ equal to 1.44 , where these choices follow Carceles-Poveda (2003). Other parameters remain the same as reported in Table 1.

Table 4 displays the results of the mean in Panel A and the RSD in Panel B for each variable. We notice that the ratio of the positive optimal aggregated dividends to salary $(d / s)$ is slightly higher in the RA model than in the VM model. The figure $0.0217(=0.19 / 8.77)$ implies that agency conflicts bring more dividends to investors' income. This result is broadly consistent with the Jensen free cash-flow hypothesis that firms will hold lower levels of cash in the presence of agency conflicts. The no-trend optimal aggregated dividends to consumption ratio in the RA model is similar to the VM model while the variances of optimal 
aggregated dividends and consumption are highly sensitive to the level of the habit persistence. With the exception of consumption and output, the relative volatility of all variables is substantially lower for the RA model than the VM model. The effect of agency conflicts leads to a substantial reduction in the volatility of dividend payments, labor hours, investment, debt financing, the wage rate and salary. For example, the RSD of dividends with $\xi=0$ is 2.44 in the VM model but only 0.06 in the RA model.

\section{[Table 4]}

Despite this, the RA model provides conclusions that are consistent with our VM results in that the greater the habit motive the smoother the consumption and the more volatile the dividend payouts. The RSD of dividend payments more than doubles from 0.06 for $\xi=0$ to 0.13 for $\xi=0.8$, while consumption volatility almost halves over the same habit motive interval from 0.30 to 0.17 . This again indicates that the aggregate optimal payout policy is highly sensitive to investor preferences, which is our central finding.

While dividends and consumption respond in similar ways to the changes in the habit motive in both the VM and RA models, this is not true for many of the other variables under consideration. Investment, for example, becomes smoother with increased $\xi$ in the RA model, contrasting with the corresponding result in the VM model. When the habit motive increases labor hours become more volatile in the RA model, while in the VM model the RSD of labor hours is largely insensitive to the habit motive. Although the variation of the wage rate increases with stronger habit motive in both models, our results show that the representative household's salary becomes smoother in the RA model while it gets more volatile in the VM model.

Table 5 presents the cyclicality results for the RA model. Consistent with the findings of Carceles-Poveda (2009) and Huang-Meier et al. (2015), optimal dividend policy is much less counter-cyclical in the RA case than the VM case. The values of $\operatorname{corr}\left(d_{t}, y_{t}\right)$ are in all cases close to the range of -0.33 to +0.54 reported by Covas and Den Haan (2011), although remain somewhat less pro-cyclical than suggested by Jermann and Quadrini (2012).

\section{[Table 5]}

Consistent with the VM model, dividends become more counter-cyclical as the habit motive increases; or, more precisely in this case, change from being pro-cyclical for $\xi \leq 0.2$ to counter-cyclical for $\xi \geq 0.3$. Interestingly the effect is non-monotonic for the RA model, with dividends becoming slightly less counter-cyclical once $\xi$ is greater than 0.6. Most 
importantly, our central finding that optimal aggregate dividend policy is highly sensitive to investor preferences is maintained for the RA case.

There are some other notable differences between the RA and VM models. In the RA case, consumption remains perfectly correlated with output for all values of $\xi$ considered. So, while consumption becomes less volatile, it does not become less pro-cyclical in the RA case, which contrasts with the value maximizing model. Labor hours, which are always highly pro-cyclical in the VM case, are always highly counter-cyclical in the RA case. This implies that the representative investor takes some of the benefits from positive technological shocks through reduced working hours. Despite this, salary remains highly pro-cyclical because of the increases in wages that results from better technology. In the RA (VM) model, labor hours becomes less counter-cyclical (the cyclicality is largely unchanged) while the wage rate becomes less (more) pro-cyclical as the habit motive increases. This leads to salaries becoming marginally less (marginally more) pro-cyclical as $\xi$ increases.

The other key difference between the RA and VM models concerns the cyclicality of debt financing. In the RA model, debt is almost uncorrelated with output, while in the VM model debt is strongly pro-cyclical for all values of $\xi$ considered. It is the VM model that is more consistent with findings on the cyclicality of corporate debt reported by both Covas and Den Haan (2011) and Jermann and Quadrini (2012). Therefore there is no strong reason to prefer either the VM or RA model over the other, but both give similar conclusions for the importance of aggregate dividends in maximizing investor welfare.

Additionally, we calculate the partial derivatives of optimal aggregated dividends with respect to the capital share to output, consumption, labor, equity price and technology shock for both the VM and RA models in the case when the habit persistence equals 0.8. We document the method and results in Appendix 4. The results of the VM model indicate that consumption, capital input and labor working hours are negatively related to the optimal aggregated dividends while the share price and technology shock are positively related to the optimal aggregated dividends. In order to maintain smooth consumption across time, the optimal aggregated dividends decrease to balance the investor's overall income. Unlike the VM model, the RA model implies a positive partial derivative between consumption and the optimal aggregated dividends. In the RA model, the household's consumption is positively related to labor.

From Figs 4 and 5, we notice that aggregate dividends respond to technology shocks with a lag. It can also be seen that the deviation of consumption from the steady state appears 
as an unexpected bump after the shock and then smooths over a ten quarter interval. Moreover, optimal consumption in the cases with and without habit motive has distinct impulse responses to technology shocks. This phenomenon is also found in optimal investment.

[Figure 4]

[Figure 5]

\section{The US economy: the cyclical volatility correlation}

This section compares the implications of our models to several key features observed in the US economy over the period 1964Q2 to 2010Q1. Specifically, we follow Jermann and Quadrini (2012) and collect quarterly financial data series from the Flow of Funds Accounts of the Federal Reserve Board (FFA) and economic data from National Income and Product Accounts (NIPA), the Bureau of Labor Statistics (BLS), and the Current Employment Statistics (CES).

A detailed definition for each series is: Equity payouts proxy for dividends $(d)$ and are the sum of net dividends of nonfarm, nonfinancial and farm business (FFA codes FA106121075 and Z1/OTHER/FA136121073), minus the total of net increases in corporate nonfinancial business and proprietors net investment in nonfinancial business (FFA codes FA103164103 and FA112090205); Consumption (c) is defined as real personal consumption expenditures (NIPA Table 1.1.6); GDP (y) is the total of real gross domestic product, from U.S. Department of Commerce: Bureau of Economic Analysis; Labor income represents salary (s) and is defined as wages times working hours. We use the data for real hourly compensation in the business sector (from BLS) for wages $(w)$ and total private aggregate weekly hours (CES, national survey) for labor working hours (I); Capital expenditures are taken from nonfinancial business from FFA Table F.101, line 4 are the measure for investment (i); Debt (b) is the total liabilities in nonfinancial business (FA144190005). All series are in billions of dollars and seasonally adjusted. Following Jermann and Quadrini (2012) we deflate equity payouts, by business value added from NIPA (Table 1.3.5) and capital expenditures and debt by the price index for business value added from NIPA (Table 1.3.4). We also deflate consumption and GDP in the same manner as equity payouts and we deflate wages following the procedure for capital expenditures.

We report the mean and RSDs of these empirical series in the final columns of Tables 2 and 4 and the correlations between series in Tables 3 and 5. Overall, the implications of 
our models are broadly consistent with the observed data. Of particular importance for this paper, both models capture the observed negative correlation between consumption and dividends except in the case of low values of $\xi$ in the RA model. They also both provide an explanation of the negative relationship between dividend and salary payments.

The different models explain different features of the observed data. The RA model with $\xi=0.3$ captures many of the characteristics of the observed correlations and is, perhaps, the best fitting model. This accurately represents the negative correlation between salary payments and dividends. However, it cannot explain the behavior of either labor hours or debt. As a consequence, as with other models, it also overestimates the importance of wages as a source of income. More generally, the RA model does better than the VM model in capturing the variation of investment and the average levels of consumption and output. By contrast, the VM model captures well the mean values of equity payouts and debt. In addition, our VM model estimates that the correlation between dividends and debt, $\operatorname{Corr}(b, d)$, lies within the range -0.34 and -0.38 , which is close to the figure of -0.40 for the empirical series. It also more accurately captures the observed values of $\operatorname{Corr}(l, c)$ and $\operatorname{Corr}(b, c)$ compared to the RA model.

Therefore, although neither model can fully capture all features of the observed economy, their implications are largely consistent with observed phenomenon. The relationship between dividends and consumption predicted by the RA model with moderate values of habit formation accurately reflects the real-world behavior that is the specific focus of this study.

\section{Conclusions}

In this paper, we study business cyclical behaviors of aggregate activities by looking at the effect of investors' preference. We demonstrate that dividends play a vital role in helping to isolate investors from the volatility of the business cycle both in the absence and presence of agency conflicts. In particular, we show that optimal dividend payout policy has increasing relative standard deviation and becomes more negatively correlated with output as the habit motive increases. This volatile and counter-cyclical stream of financial income helps counterbalance the highly pro-cyclical nature of salaries in economies when the habit motive is strong.

Using a macroeconomic dynamic stochastic general equilibrium approach to study the relationship between aggregate dividend policy and investor utility, we provide a formal 
theoretical framework to support the conjecture by Marsh and Merton (1987) that aggregate dividend policy remains relevant even when investors are less concerned about which individual firm services this demand for equity income. Our study sheds light on the relationship between aggregate dividend policy and investor utility; an issue that has rarely been previously discussed in the standard corporate finance literature. We believe that this opens a large number of areas for future research. This work could be extended, for example, by examining optimal aggregate dividend and investment policy in an economy with irreversible investment.

A further important potential extension would be to apply generalized method of moments (GMM) methods to estimate and test the moment conditions of this framework. This would follow in the path of a number of empirical studies, including Yogo (2006), who applies GMM to test the moment conditions of models that use durable consumption to explain expected stock returns. Darrat et al. (2011) also use GMM to estimate and test their model that provides evidence of the existence of idiosyncratic consumption risk sharing across countries, while Savov (2011) implements a similar approach to test a consumptionbased capital asset pricing model that introduces garbage growth as a measure of consumption growth. Verifying the robustness of our findings to these additional tests would provide further support to our conclusion that aggregate dividends play a vital role in helping investors optimally smooth their consumption paths.

\section{References}

Alessandrini, F. (2003) Introducing capital structure in a production economy: Implications for investment, debt and dividends, available at https://ideas.repec.org/p/lau/crdeep/03.03.html.

Allen, F. and Michaely, R. (2003) Payout policy, in G.M. Constantinides, M. Harris, and R.M. Stulz (eds), Handbook of the Economics of Finance, Elsevier, North Holland.

Bansal, R. and Yaron, A. (2004) Risks for the long run: a potential resolution of asset pricing puzzles, Journal of Finance, 59, 1481-509.

Baxter, M., Jermann, U., and King, R. (1998) Nontraded goods, nontraded factors, and international non-diversification, Journal of International Economics, 44, 211-29.

Ben-David, I. (2010) Dividend policy decisions, in H.K. Baker and J.R. Nofsinger (eds), Behavioral Finance: Investors, Corporations, and Markets, John Wiley \& Sons.

Benartzi, S., Michaely, R., and Thaler, R. (1997) Do changes in dividends signal the future or the past?, Journal of Finance, 52, 1007-34.

Bhattacharya, S. (1979) Imperfect information, dividend policy, and the bird in the hand 
fallacy, Bell Journal of Economics, 10, 259-70.

Boldrin, M., Christiano, L., and Fisher, J. (2001) Habit persistence, asset returns, and the business cycle, American Economic Review, 91, 149-66.

Brav, A., Graham, J., Harvey, C., and Michaely, R. (2005) Payout policy in the 21st century, Journal of Financial Economics, 77, 483-527.

Brennan, M. (1970) Taxes, market valuation and corporate financial policy, National Tax Journal, 23, 417-27.

Campbell, J. (1994) Inspecting the mechanism: an analytical approach to the stochastic growth model, Journal of Monetary Economics, 33, 463-506.

Campbell, J.Y. and Cochrane, J.H. (1999) By force of habit: a consumption-based explanation of aggregate stock market behavior, Journal of Political Economy, 107, 20551.

Carceles-Poveda, E. (2003) Capital adjustment costs and firm risk aversion, Economics Letters, 81, 101-7.

Carceles-Poveda, E. (2005) Idiosyncratic shocks and asset returns in the real-business-cycle model: an approximate analytical approach, Macroeconomic Dynamics, 9, 295-320.

Carceles-Poveda, E. (2009) Asset prices and business cycles under market incompleteness, Review of Economic Dynamics, 12, 405-22.

Carroll, C., Overland, J., and Weil, D. (2000) Saving and growth with habit formation, American Economic Review, 90, 341-55.

Constantinides, G. (1990) Habit formation: a resolution of the equity premium puzzle, Journal of Political Economy, 98, 519-43.

Covas, F. and Den Haan, W. (2011) The cyclical behavior of debt and equity finance, American Economic Review, 101, 877-99.

Darrat, A.F., Li, B., and Park, J.C. (2011) Consumption-based CAPM models: international evidence, Journal of Banking \& Finance, 35, 2148-57.

DeAngelo, H., DeAngelo, L., and Skinner, D. (1996) Reversal of fortune dividend signaling and the disappearance of sustained earnings growth, Journal of Financial Economics, 40, 341-71.

Dennis, R. (2009) Consumption habits in a new Keynesian business cycle model, Journal of Money, Credit and Banking, 41, 1015-30.

Dong, M., Robinson, C., and Veld, C. (2005) Why individual investors want dividends, Journal of Corporate Finance, 12, 121-58.

Easterbrook, F. (1984) Two agency-cost explanations of dividends, American Economic Review, 74, 650-9.

Fuhrer, J. (2000) Habit formation in consumption and its implications for monetary-policy models, American Economic Review, 90, 367-90.

Fuller, K. and Goldstein, M. (2011) Do dividends matter more in declining markets?, Journal of Corporate Finance, 17, 457-73.

Gershun, N. (2010) Habit persistence, impediments to production factor adjustments, and asset returns in general equilibrium models with self-fulfilling expectations, Review of 
Financial Economics, 19, 19-27.

Hansen, G. (1985) Indivisible labor and the business cycle, Journal of Monetary Economics, 16, 309-27.

Harris, T., Hubbard, R., and Kemsley, D. (2001) The share price effects of dividend taxes and tax imputation credits, Journal of Public Economics, 79, 569-96.

Hirshleifer, D. A., Li, J., and Yu, J. (2015) Asset pricing in production economies with extrapolative expectations, available at http://dx.doi.org/10.2139/ssrn.1785961.

Huang-Meier, W., Freeman, M. C., and Mazouz, K. (2015) Why are aggregate equity payouts pro-cyclical?, Journal of Macroeconomics, 44, 98-108.

Jensen, M. (1986) Agency costs of free cash flow, corporate finance, and takeovers, American Economic Review, 76, 323-9.

Jensen, M. and Meckling, W. (1976) Theory of the firm: managerial behavior, agency costs, and Capital Structure, Journal of Financial Economics, 3, 305-60.

Jermann, U. and Quadrini, V. (2012) Macroeconomic effects of financial shocks, American Economic Review, 102, 238-71.

Ju, N. and Miao, J. (2012) Ambiguity, learning, and asset returns, Econometrica, 80, 55991.

Kydland, F. and Prescott, E. (1982) Time to build and aggregate fluctuations, Econometrica: Journal of the Econometric Society, 50, 1345-70.

La Porta, R., Lopez-de Silanes, F., Shleifer, A., and Vishny, R. (2000) Agency problems and dividend policies around the world, Journal of Finance, 55, 1-33.

Leland, H. (1972) Theory of the firm facing uncertain demand, American Economic Review, 62, 278-91.

Lettau, M., and Uhlig, H. (2000) Can habit formation be reconciled with business cycle facts?, Review of Economic Dynamics, 3, 79-99.

Levy, A. and Hennessy, C. (2007) Why does capital structure choice vary with macroeconomic conditions?, Journal of Monetary Economics, 54, 1545-64.

Liu, H. and Miao, J. (2015) Growth uncertainty, generalized disappointment aversion and production-based asset pricing, Journal of Monetary Economics, 69, 70-89.

Marsh, T. and Merton, R. (1987) Dividend behavior for the aggregate stock market, Journal of Business, 60, 1-40.

Miller, M. H. and Modigliani, F. (1961) Dividend policy, growth, and the valuation of shares, Journal of Business, 34, 411-33.

Miller, M. H. and Rock, K. (1985) Dividend policy under asymmetric information, Journal of Finance, 40, 1031-51.

Miller, M. and Scholes, M. (1978) Dividends and taxes, Journal of Financial Economics, 6, 333-64.

Modigliani, F. and Miller, M. H. (1963) Corporate income taxes and the cost of capital: a correction, American Economic Review, 53, 433-43.

Otrok, C., Ravikumar, B., and Whiteman, C. (2002) Habit formation: a resolution of the 
equity premium puzzle?, Journal of Monetary Economics, 49, 1261-88.

Pettit, R. (1977) Taxes, transactions costs and the clientele effect of dividends, Journal of Financial Economics, 5, 419-36.

Poterba, J. and Summers, L. (1985) The economic effects of dividend taxation, available at http://www.nber.org/papers/w1353.

Radner, R. (1970) Problems in the theory of markets under uncertainty, American Economic Review, 60, 454-60.

Sandmo, A. (1971) On the theory of the competitive firm under price uncertainty, American Economic Review, 61, 65-73.

Savov, A. (2011) Asset pricing with garbage, Journal of Finance, 66, 177-201.

Seckin, A. (2001) Consumption-leisure choice with habit formation, Economics Letters, 70, 115-20.

Yogo, M. (2006) A consumption-based explanation of expected stock returns, Journal of Finance, 61, 539-80. 


\section{Appendices}

\section{Appendix 1: Proof of eqs (17) to (21) (Equilibrium conditions for the economy} environment including a representative household and a value-maximizing firm)

First, the representative household's optimal problem (eq. (2)) is solved by:

$$
\max _{c_{t}, l_{t}^{s}, n_{t}, b_{t}^{H}} \sum_{h=0}^{\infty} \beta^{h} u\left(c_{t+h}, c_{t+h-1}, 1-l_{t+h}^{s}\right)
$$

subject to the budget constraint (eq. (3))

$$
c_{t}+q_{t} n_{t+1}+b_{t}^{H} \leq w_{t} l_{t}^{s}+\left(q_{t}+d_{t}\right) n_{t}+R_{f t-1} b_{t-1}^{H}
$$

The Lagrangian of the household's optimal problem can be written as:

$$
\begin{aligned}
L=E_{t}\left\{\sum_{h=0}^{\infty} \beta^{h}\right. & {\left[u\left(c_{t+h}, c_{t+h-1}, 1-l_{t+h}^{s}\right)\right.} \\
& -\lambda_{t+h}\left(c_{t+h}+q_{t+h} n_{t+h+1}+b_{t+h}^{H}-w_{t+h} l_{t+h}^{s}-q_{t+h} n_{t+h}\right. \\
& \left.\left.\left.-d_{t+h} n_{t+h}-R_{f t+h-1} b_{t+h-1}^{h}\right)\right]\right\}
\end{aligned}
$$

where $\lambda_{t+h}$ is a Lagrangian multiplier. Solving for the first-order conditions yields:

$$
\begin{aligned}
\frac{\partial L}{\partial c_{t}} & =0 \Rightarrow \lambda_{t}=\frac{\partial u\left(c_{t}, c_{t-1}, 1-l_{t}^{s}\right)}{\partial c_{t}}+\beta \frac{\partial u\left(c_{t+1}, c_{t}, 1-l_{t+1}^{s}\right)}{\partial c_{t}} \\
\frac{\partial L}{\partial l_{t}^{s}} & =0 \Rightarrow \frac{\partial u\left(c_{t}, c_{t-1}, 1-l_{t}^{S}\right)}{\partial l_{t}^{s}}+\lambda_{t} w_{t}=0 \\
\frac{\partial L}{\partial n_{t}} & =0 \Rightarrow q_{t}=\beta E_{t}\left[\left(\frac{\lambda_{t+1}}{\lambda_{t}}\right)\left(q_{t+1}+d_{t+1}\right)\right] \\
\frac{\partial L}{\partial b_{t}^{H}} & =0 \Rightarrow \lambda_{t}=\beta E_{t}\left[\lambda_{t+1} R_{f t}\right]
\end{aligned}
$$

Substituting the Lagrangian multiplier $\lambda_{t}$ from eq. (A.2) into eq. (A.3), the wage rate for labor in supply is:

$$
w_{t}=-\frac{\frac{\partial u\left(c_{t}, c_{t-1}, 1-l_{t}^{s}\right)}{\partial l_{t}^{s}}}{\frac{\partial u\left(c_{t}, c_{t-1}, 1-l_{t}^{s}\right)}{\partial c_{t}}+\beta \frac{\partial u\left(c_{t+1}, c_{t}, 1-l_{t+1}^{s}\right)}{\partial c_{t}}}
$$

Eq. (A.4) leads a standard Euler equation for the price of equity:

$$
q_{t}=E_{t}\left[M_{t, 1}\left(q_{t+1}+d_{t+1}\right)\right] \text { where } M_{t, 1}=\beta\left(\frac{\lambda_{t+1}}{\lambda_{t}}\right)
$$


where $M_{t, 1}$ is defined as the intertemporal marginal rate of substitution with respect to consumption.

Rewriting eq. (A.5) with $M_{t, 1}$, we obtain the the standard Euler equation:

$$
1=E_{t}\left[M_{t, 1} R_{f t}\right]
$$

So that the above eqs (A.6), (A.7), and (A.8) are the household's optimal first order conditions.

Next, we solve the representative firm's optimal problem (eq. (14)):

$$
\max _{l_{t}^{d}, k_{t}, b_{t}} d_{t}+E_{t}\left[\sum_{h=1}^{\infty} M_{t, h} d_{t+h}\right]
$$

subject to the constraints of the capital function (eq. (7)) and dividends to shareholders (eq. (9)):

$$
d_{t}=(1-\tau)\left[k_{t-1}^{\alpha}\left(z_{t} l_{t}^{d}\right)^{1-\alpha}-w_{t} l_{t}^{d}-R_{t-1} b_{t-1}\right]-\tau b_{t-1}+b_{t}-k_{t}+(1-\eta) k_{t-1}
$$

The Lagrangian of the firm's optimization problem can be written as:

$$
\begin{aligned}
L=(1-\tau)\left[k_{t-1}^{\alpha}\left(z_{t} l_{t}^{d}\right)^{1-\alpha}-w_{t} l_{t}^{d}-R_{t-1} b_{t-1}\right]-\tau b_{t-1}+b_{t}-k_{t} \\
+(1-\eta) k_{t-1} \\
\quad+E_{t}\left\{\sum _ { h = 1 } ^ { \infty } M _ { t , h } ( 1 - \tau ) \left[k_{t-1+h}^{\alpha}\left(z_{t+h} l_{t+h}^{d}\right)^{1-\alpha}-w_{t+h} l_{t+h}^{d}\right.\right. \\
\left.\left.\quad-R_{t-1+h} b_{t-1+h}\right]-\tau b_{t-1+h}+b_{t+h}-k_{t+h}+(1-\eta) k_{t-1+h}\right\}
\end{aligned}
$$

Differentiating eq. (A.10) with respect to $l_{t}^{d}, k_{t}$ and $b_{t}$ and setting the values each time to zero yields:

$$
\begin{aligned}
& \frac{\partial L}{\partial l_{t}^{d}}=0 \Rightarrow w_{t}=(1-\alpha) k_{t-1}^{\alpha}\left(z_{t}\right)^{1-\alpha} l_{t}^{-\alpha} \Rightarrow w_{t}=(1-\alpha) \frac{y_{t}}{l_{t}} \\
& \frac{\partial L}{\partial k_{t}}=0 \Rightarrow 1=E_{t}\left\{M_{t, 1}\left\{\left[(1-\tau) \alpha k_{t}^{\alpha-1}\left(z_{t+1} l_{t+1}\right)^{1-\alpha}\right]+1-\eta\right\}\right\} \\
& \frac{\partial L}{\partial b_{t}}=0 \Rightarrow 1=E_{t}\left\{M_{t, 1}\left[(1-\tau) R_{t}+\tau\right]\right\}
\end{aligned}
$$


Using eqs (A.6) to (A.8) and (A.11) to (A.13), we can derive the value-maximizing model's equilibrium conditions. Specifically, using eqs (A.6) and (A.11), the optimal wage rate for labor takes the following form:

$$
(1-\alpha) \frac{y_{t}}{l_{t}}=-\frac{\frac{\partial u\left(c_{t}, c_{t-1}, 1-l_{t}^{s}\right)}{\partial l_{t}^{s}}}{\frac{\partial u\left(c_{t}, c_{t-1}, 1-l_{t}^{s}\right)}{\partial c_{t}}+\beta \frac{\partial u\left(c_{t+1}, c_{t}, 1-l_{t+1}^{s}\right)}{\partial c_{t}}}
$$

Using eqs (A.8) and (A.12), we get:

$$
\begin{gathered}
1=E_{t}\left[M_{t, 1} R_{f t}\right] \\
R_{f t}=(1-\tau) \alpha k_{t}^{\alpha-1}\left(z_{t+1} l_{t+1}\right)^{1-\alpha}+1-\eta
\end{gathered}
$$

Using eqs (A.8) and (A.13), the relationship between the risk-free interest rate and the corporate interest rate is:

$$
R_{f t}=(1-\tau) R_{t}+\tau \Rightarrow R_{t}=\left(\frac{1}{1-\tau}\right)\left[R_{f t}-\tau\right]
$$

For the price of equity, we rewrite eq. (A.7) here:

$$
q_{t}=E_{t}\left[M_{t, 1}\left(q_{t+1}+d_{t+1}\right)\right]
$$

So that eqs (A.14) to (A.18) are the equilibrium conditions eqs (17) to (21) shown in Section 2.1.5. We show a specific form of $M_{t, 1}$ in Appendix 2.

\section{Appendix 2: The intertemporal marginal rate of substitution with consumption, $M$}

In eq. (A.7), we define the intertemporal marginal rate of substitution in the following form:

From eq. (A.2), we know that:

$$
M_{t, 1} \equiv \beta \frac{\lambda_{t+1}}{\lambda_{t}}
$$

$$
\begin{gathered}
\lambda_{t}=\frac{\partial u\left(c_{t}, c_{t-1}, 1-l_{t}^{s}\right)}{\partial c_{t}}+\beta \frac{\partial u\left(c_{t+1}, c_{t}, 1-l_{t+1}^{s}\right)}{\partial c_{t}} \\
\lambda_{t+1}=\frac{\partial u\left(c_{t+1}, c_{t}, 1-l_{t+1}^{s}\right)}{\partial c_{t+1}}+\beta \frac{\partial u\left(c_{t+2}, c_{t+1}, 1-l_{t+2}^{s}\right)}{\partial c_{t+1}}
\end{gathered}
$$

Substituting eqs (A.20) and (A.21) into eq. (A.19):

$$
M_{t, h} \equiv \beta^{h} \frac{\lambda_{t+h}}{\lambda_{t}}=\beta^{h} \frac{\frac{\partial u\left(c_{t+h}, c_{t+h-1}, 1-l_{t+h}^{s}\right)}{\partial l_{t}^{s}}+\frac{\partial u\left(c_{t+h+1}, c_{t+h}, 1-l_{t+h+1}^{s}\right)}{\partial l_{t}^{s}}}{\frac{\partial u\left(c_{t}, c_{t-1}, 1-l_{t}^{s}\right)}{\partial c_{t}}+\beta \frac{\partial u\left(c_{t+1}, c_{t}, 1-l_{t+1}^{s}\right)}{\partial c_{t}}}
$$


Next, we apply the household's momentary utility function to eq. (A.22). We assume that household utility is determined by the multiplied effect of consumption and leisure, which can be written as:

$$
u\left(c_{t}, c_{t-1}, 1-l_{t}\right)=\frac{\left[\left(c_{t}-\xi c_{t-1}\right)^{\rho}\left(1-l_{t}\right)^{1-\rho}\right]^{1-\gamma}}{1-\gamma}
$$

With the given momentary utility function, we calculate $\partial u_{t} / c_{t}, \partial u_{t+1} / c_{t}, \partial u_{t} / l_{t}, \partial u_{t+1} /$ $c_{t+1}, \partial u_{t+2} / c_{t+1}, \lambda_{t}$ and $\lambda_{t+1}$ :

$$
\begin{aligned}
& \frac{\partial u_{t}}{\partial c_{t}}=\left[\left(c_{t}-\xi c_{t-1}\right)^{\rho}\left(1-l_{t}\right)^{1-\rho}\right]^{-\gamma}\left[\rho\left(c_{t}-\xi c_{t-1}\right)^{\rho-1}\left(1-l_{t}\right)^{1-\rho}\right] \\
& \frac{\partial u_{t+1}}{\partial c_{t}}=\left[\left(c_{t+1}-\xi c_{t}\right)^{\rho}\left(1-l_{t+1}\right)^{1-\rho}\right]^{-\gamma}\left[(-\xi) \rho\left(c_{t+1}-\xi c_{t}\right)^{\rho-1}\left(1-l_{t+1}\right)^{1-\rho}\right] \\
& \frac{\partial u_{t}}{\partial l_{t}}=\left[\left(c_{t}-\xi c_{t-1}\right)^{\rho}\left(1-l_{t}\right)^{1-\rho}\right]^{-\gamma}\left[(-1)(1-\rho)\left(c_{t}-\xi c_{t-1}\right)^{\rho}\left(1-l_{t}\right)^{-\rho}\right] \\
& \frac{\partial u_{t+1}}{\partial c_{t+1}}=\left[\left(c_{t+1}-\xi c_{t}\right)^{\rho}\left(1-l_{t+1}\right)^{1-\rho}\right]^{-\gamma}\left[\rho\left(c_{t+1}-\xi c_{t}\right)^{\rho-1}\left(1-l_{t+1}\right)^{1-\rho}\right] \\
& \frac{\partial u_{t+2}}{\partial c_{t+1}}=\left[\left(c_{t+2}-\xi c_{t+1}\right)^{\rho}\left(1-l_{t+2}\right)^{1-\rho}\right]^{-\gamma}\left[(-\xi) \rho\left(c_{t+2}-\xi c_{t+1}\right)^{\rho-1}\left(1-l_{t+2}\right)^{1-\rho}\right] \\
& \lambda_{t}=\frac{\partial u_{t}}{\partial c_{t}}+\beta \frac{\partial u_{t+1}}{\partial c_{t}} \\
& \lambda_{t+1}=\frac{\partial u_{t+1}}{\partial c_{t+1}}+\beta \frac{\partial u_{t+2}}{\partial c_{t+1}}
\end{aligned}
$$

Finally, the intertemporal marginal rate of substitution with consumption can be written as:

$$
M_{t, 1} \equiv \beta \frac{\lambda_{t+1}}{\lambda_{t}}=\beta\left(\frac{1-\left[\xi \beta\left(\frac{c_{t+2}-\xi c_{t+1}}{c_{t+1}-\xi c_{t}}\right)^{-\gamma \rho+\rho-1}\left(\frac{1-l_{t+2}}{1-l_{t+1}}\right)^{-\gamma(1-\rho)+1-\rho}\right.}{\left[\left(\frac{c_{t}-\xi c_{t-1}}{c_{t+1}-\xi c_{t}}\right)^{-\gamma \rho+\rho-1}\left(\frac{1-l_{t}}{1-l_{t+1}}\right)^{-\gamma(1-\rho)+1-\rho}\right]-\xi \beta}\right)
$$

\section{Appendix 3: Proof of eqs (23) to (27) (Equilibrium conditions for the economy environment including a representative household and a risk-averse firm)}

This appendix obtains equilibrium conditions when the firm no longer maximizes shareholders' value but instead possesses its own risk aversion characteristic.

The household's maximization preference does not change and therefore the first order conditions for the household's problem remain the same as in the case of the valuemaximization model as given in eqs (A.6), (A.7), and (A.8).

To solve the risk-averse firm's problem (eq. (22)): 


$$
\max _{l_{t}^{d}, k_{t}, b_{t}} E_{t}\left[\sum_{h=1}^{\infty} \phi^{h} \frac{d_{t+h}^{1-\gamma_{F}}-1}{1-\gamma_{F}}\right]
$$

subject to the constraint of dividends to shareholders (eq. (9), where $i$ is replaced by eq. (7)):

$$
d_{t}=(1-\tau)\left[k_{t-1}^{\alpha}\left(z_{t} l_{t}^{d}\right)^{1-\alpha}-w_{t} l_{t}^{d}-R_{t-1} b_{t-1}\right]-\tau b_{t-1}+b_{t}-k_{t}+(1-\eta) k_{t-1}
$$

Setting the partial derivatives of the firm's objective function with respect to $l, k$, and $b$ all equal to zero, the first order conditions for the firm's problem are:

$$
\begin{aligned}
& \frac{\partial L}{\partial l_{t}^{d}}=0 \Rightarrow w_{t}=(1-\alpha) k_{t-1}^{\alpha}\left(z_{t}\right)^{1-\alpha} l_{t}^{-\alpha} \Rightarrow w_{t} l_{t}=(1-\alpha) y_{t} \\
& \frac{\partial L}{\partial k_{t}}=0 \Rightarrow 1=\phi E_{t}\left\{\left(\frac{d_{t}}{d_{t+1}}\right)^{\gamma_{F}}\left\{\left[(1-\tau) \alpha k_{t}^{\alpha-1}\left(z_{t+1} l_{t+1}\right)^{1-\alpha}\right]+1-\eta\right\}\right\} \\
& \frac{\partial L}{\partial b_{t}}=0 \Rightarrow 1=\phi E_{t}\left\{\left(\frac{d_{t}}{d_{t+1}}\right)^{\gamma_{F}}\left[(1-\tau) R_{t}+\tau\right]\right\}
\end{aligned}
$$

The above eqs (A.34) to (A.36) are the risk-averse firm's optimal conditions.

The next step is to tidy up the six first order conditions (eqs (A.6) to (A.8) and (A.34) to (A.36)). From eqs (A.6) and (A.34), we know that the optimal wage rate for labor takes the following form:

$$
(1-\alpha) \frac{y_{t}}{l_{t}}=-\frac{\frac{\partial u\left(c_{t}, c_{t-1}, 1-l_{t}^{s}\right)}{\partial l_{t}^{s}}}{\frac{\partial u\left(c_{t}, c_{t-1}, 1-l_{t}^{s}\right)}{\partial c_{t}}+\beta \frac{\partial u\left(c_{t+1}, c_{t}, 1-l_{t+1}^{s}\right)}{\partial c_{t}}}
$$

From eqs (A.8) and (A.35):

$$
\begin{gathered}
1=\phi E_{t}\left[\left(\frac{d_{t}}{d_{t+1}}\right)^{\gamma_{F}} R_{f t}\right] \\
R_{f t}=(1-\tau) \alpha k_{t}^{\alpha-1}\left(z_{t+1} l_{t+1}\right)^{1-\alpha}+1-\eta
\end{gathered}
$$

where $\phi\left(\frac{d_{t}}{d_{t+1}}\right)^{\gamma_{F}}$ can be regarded as being the equivalent to $M_{t, 1}$ from the value-maximizing model.

Using eqs (A.8) and (A.36), we can obtain the relationship between the risk-free interest rate and the corporate interest rate in the absence of bankruptcy:

$$
R_{f t}=(1-\tau) R_{t}+\tau \Rightarrow R_{t}=\left(\frac{1}{1-\tau}\right)\left[R_{f t}-\tau\right]
$$

For the price of equity, we repeat eq. (A.7) here:

$$
q_{t}=E_{t}\left[M_{t, 1}\left(q_{t+1}+d_{t+1}\right)\right]
$$


So that eqs (A.37) to (A.41) are the equilibrium conditions eqs (23) to (27) shown in Section 3. The variable $M_{t, 1}$ includes the household's utility function with habit formation; refer to Appendix 2 for details.

Appendix 4: The partial derivatives of dividends with respect to explanatory variables

Consider the optimal aggregated dividend as a linear function of underlying variables:

$$
d=a_{0}+a_{1} k+a_{2} c+a_{3} l+a_{4} q+a_{5} Z
$$

To derive the partial derivative of dividends with respect to each variable, we first construct a 5 -vector of the covariance of each explanatory variable with $d ; Y=\operatorname{Cov}(d, x)$. We also construct a variance-covariance matrix of all explanatory variables, $X$, with the ith row given by $\operatorname{Cov}\left(x^{T}, x_{i}\right)$, and a 5 -vector, $a$, with elements $a_{i}$ that denote the partial derivatives:

$$
\begin{aligned}
& \operatorname{Cov}\left(d, x_{i}\right)=\operatorname{Cov}\left(a_{0}+a_{1} k+a_{2} c+a_{3} l+a_{4} q+a_{5} z, x_{i}\right) \\
& \Rightarrow \operatorname{Cov}\left(d, x_{i}\right)=\sum_{j=1}^{5} a_{j} \operatorname{Cov}\left(x_{j}, x_{i}\right) \\
& \Rightarrow Y=X a \\
& \Rightarrow a=X^{-1} Y
\end{aligned}
$$

We calculate the partial derivative of the optimal aggregated dividends with respect to capital input $(k)$, consumption $(c)$, labor $(l)$, equity price $(q)$ and technology shock $(z)$ for the VM model and the RA model in the case of habit persistence of 0.8 :

\begin{tabular}{ccc} 
Model & VM & RA \\
\hline$\partial d / \partial k$ & -0.212 & 0.002 \\
$\partial d / \partial c$ & -1.796 & 0.144 \\
$\partial d / \partial l$ & -9.600 & 0.102 \\
$\partial d / \partial q$ & 0.436 & 0.002 \\
$\partial d / \partial z$ & 1.132 & -0.082
\end{tabular}




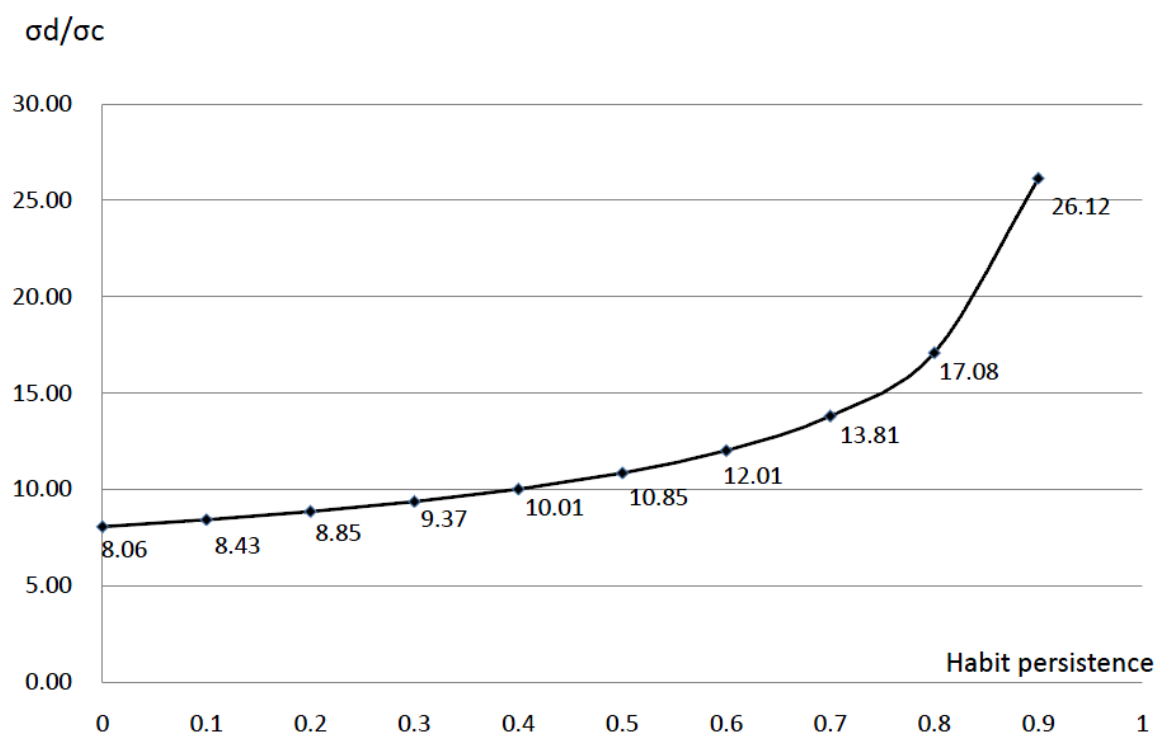

Fig. 1. Sensitivity of aggregate dividends and consumption to the habit motive 


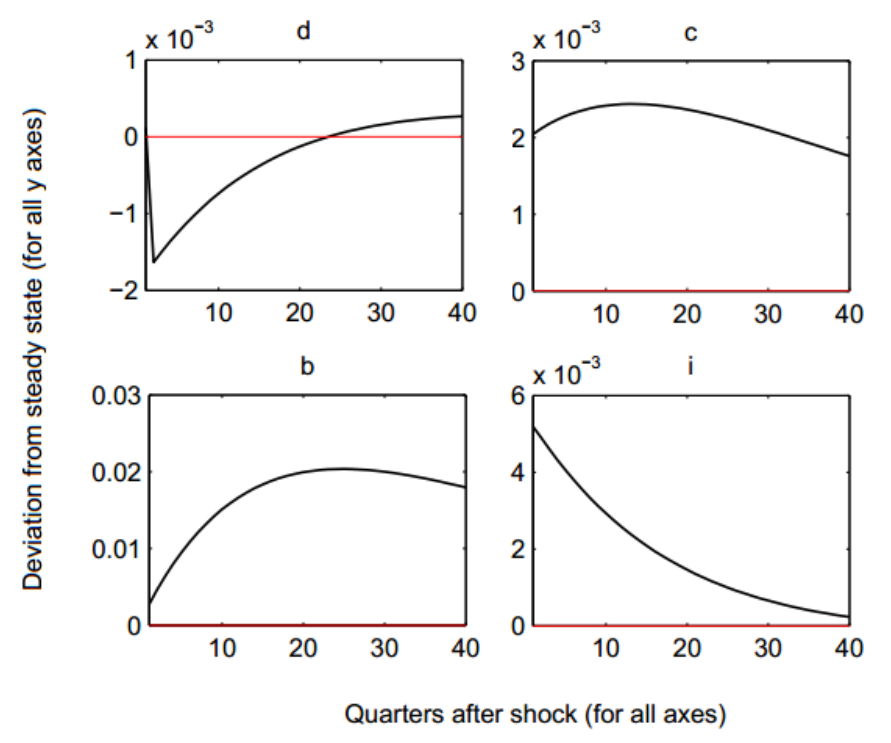

Fig. 2. The impulse responses of optimal aggregate dividends $(d)$, consumption $(c)$, debt $(b)$, and investment $(i)$ in the case without habit persistence for the $\mathrm{VM}$ model $(\xi=0)$

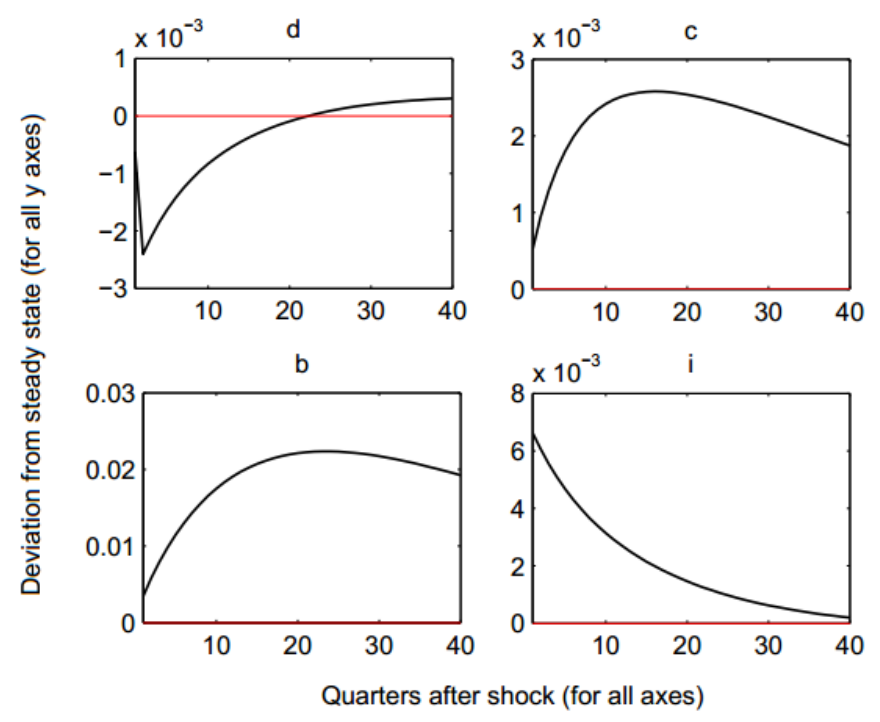

Fig. 3. The impulse responses of optimal aggregate dividends $(d)$, consumption $(c)$, debt $(b)$, and investment $(i)$ in the case with habit persistence for the $\mathrm{VM}$ model $(\xi=0.8)$ 


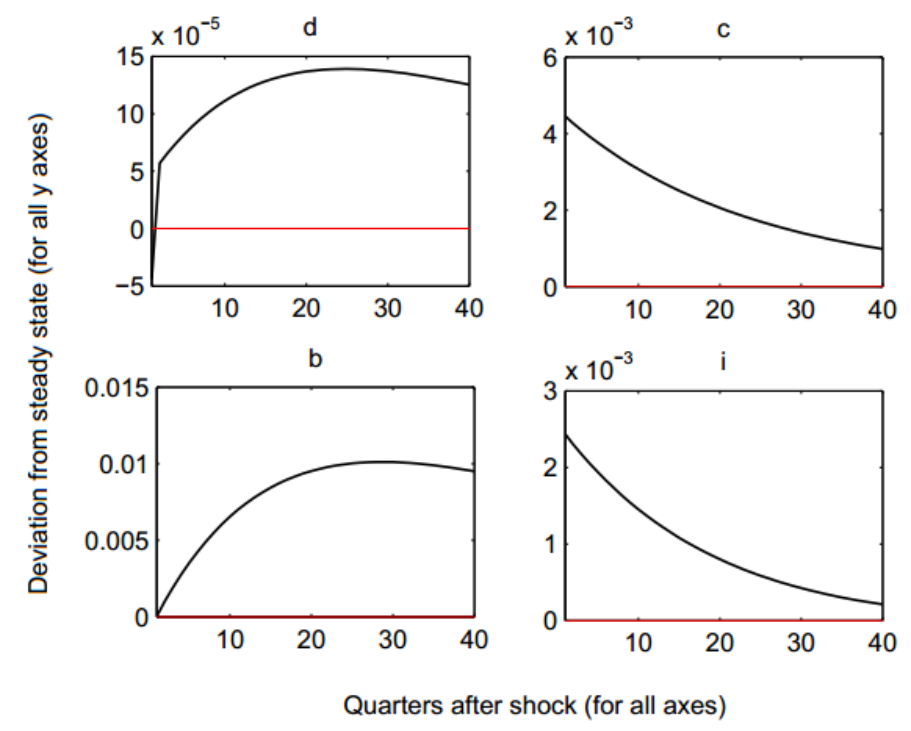

Fig. 4. The impulse responses of optimal aggregate dividends $(d)$, consumption $(c)$, debt $(b)$, and investment $(i)$ in the case without habit persistence for the RA model $(\xi=0)$

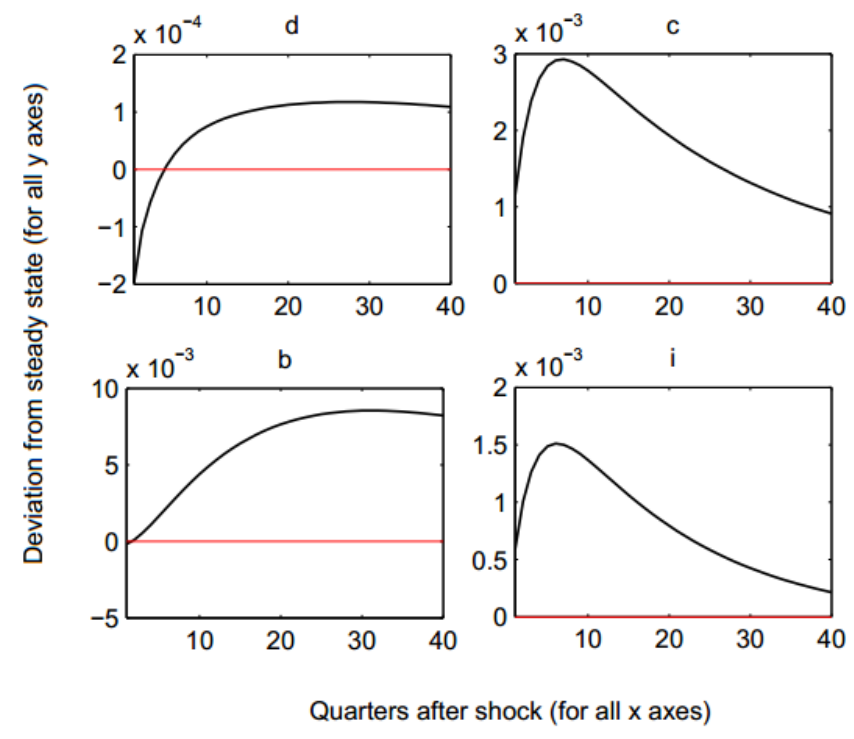

Fig. 5. The impulse responses of optimal aggregate dividends $(d)$, consumption $(c)$, debt $(b)$, and investment $(i)$ in the case with habit persistence for the RA model $(\xi=0.8)$ 
Table 1. Calibration values for the models' parameters

\begin{tabular}{llcr}
\hline & Parameters & Notation & Value \\
\hline 1 & Capital share to output & $\alpha$ & 0.35 \\
2 & Depreciation ratio & $\eta$ & 0.019 \\
3 & Subjective time discount factor & $\beta$ & 0.99 \\
4 & Persistence of the technology shock & $\psi$ & 0.95 \\
5 & Standard deviation of the technology shock & $\sigma_{\mathcal{E}}$ & 0.00712 \\
6 & Recovery rate & $\theta$ & 0.92 \\
7 & Tax rate & $\tau$ & 0.06 \\
8 & Time allocated to market activities & $\rho$ & 0.36 \\
9 & Coefficient of relative risk aversion of the household & $\gamma$ & 2 \\
10 & Upper bound & $U$ & 1.225 \\
11 & Lower bound & $L$ & 0.475 \\
12 & Habit persistence & $\xi$ & Given \\
\hline
\end{tabular}

This table displays a summary of parameter values. Rows 1-7 are taken from Alessandrini (2003). Row 8 is taken from Campbell (1994). Rows 9 - 11 are values commonly used in literature. Habit persistence is allowed to take a range of different values from 0 to 0.8 with an interval of $10 \%$. 
Table 2. Mean and relative standard deviation (RSD in \%) for the VM model and the US economy

\begin{tabular}{|c|c|c|c|c|c|c|c|c|c|c|}
\hline & \multicolumn{9}{|c|}{$\xi$} & \multirow{2}{*}{$\begin{array}{c}\text { U.S. } \\
\text { Economy }\end{array}$} \\
\hline & 0 & 0.1 & 0.2 & 0.3 & 0.4 & 0.5 & 0.6 & 0.7 & 0.8 & \\
\hline \multicolumn{11}{|c|}{ Panel A: Mean } \\
\hline$d$ & 0.09 & 0.09 & 0.09 & 0.09 & 0.09 & 0.09 & 0.09 & 0.09 & 0.09 & 0.02 \\
\hline$c$ & 0.91 & 0.91 & 0.92 & 0.92 & 0.92 & 0.92 & 0.92 & 0.93 & 0.94 & 1.91 \\
\hline$y$ & 1.19 & 1.19 & 1.19 & 1.20 & 1.20 & 1.20 & 1.20 & 1.21 & 1.22 & 3.06 \\
\hline$l$ & 0.32 & 0.32 & 0.32 & 0.32 & 0.32 & 0.33 & 0.33 & 0.33 & 0.33 & 2.39 \\
\hline$i$ & 0.26 & 0.26 & 0.26 & 0.26 & 0.26 & 0.26 & 0.26 & 0.26 & 0.26 & 9.05 \\
\hline$b$ & 5.40 & 5.40 & 5.41 & 5.41 & 5.42 & 5.43 & 5.45 & 5.48 & 5.54 & 5.23 \\
\hline$w$ & 27.38 & 27.36 & 27.33 & 27.30 & 27.25 & 27.19 & 27.10 & 26.95 & 26.66 & 1.46 \\
\hline$s$ & 8.84 & 8.84 & 8.84 & 8.84 & 8.84 & 8.84 & 8.84 & 8.84 & 8.84 & 3.24 \\
\hline \multicolumn{11}{|c|}{ Panel B: Relative standard deviation (RSD) in \% } \\
\hline$d$ & 2.44 & 2.42 & 2.42 & 2.44 & 2.49 & 2.59 & 2.73 & 2.94 & 3.21 & 1.37 \\
\hline$c$ & 0.30 & 0.30 & 0.29 & 0.29 & 0.28 & 0.27 & 0.26 & 0.24 & 0.21 & 1.80 \\
\hline$y$ & 0.85 & 0.85 & 0.85 & 0.85 & 0.85 & 0.85 & 0.85 & 0.85 & 0.84 & 1.69 \\
\hline$l$ & 0.38 & 0.38 & 0.38 & 0.38 & 0.38 & 0.38 & 0.37 & 0.37 & 0.36 & 0.21 \\
\hline$i$ & 2.66 & 2.69 & 2.73 & 2.77 & 2.83 & 2.90 & 2.99 & 3.10 & 3.22 & 0.40 \\
\hline$b$ & 0.19 & 0.19 & 0.19 & 0.19 & 0.19 & 0.20 & 0.20 & 0.21 & 0.22 & 0.87 \\
\hline$w$ & 2.87 & 2.86 & 2.87 & 2.90 & 2.97 & 3.07 & 3.22 & 3.43 & 3.71 & 0.40 \\
\hline$s$ & 3.17 & 3.17 & 3.19 & 3.23 & 3.29 & 3.40 & 3.55 & 3.76 & 4.03 & 0.19 \\
\hline
\end{tabular}

The table reports the mean and the relative standard deviations (\%) of aggregate dividends $(d)$, consumption $(c)$, labor $(l)$, output $(y)$, capital $(k)$, investment $(i)$, debt $(d)$, wages rate $(w)$ and salary $(s)$, generated from the value-maximizing model. $\xi$ is persistence of habit in consumption. The extended equilibrium model is incorporated with aggregate dividend policy and with different values of habit persistence. All data are detrended by Hodrick and Prescott filter (HP filter). The multiplier of the HP filter is 1600 . For U.S. economy, we collect quarterly financial data from the Flow of Funds Accounts of the Federal Reserve Board (FFA) and economic data from National Income and Product Accounts (NIPA), the Bureau of Labor Statistics (BLS) and the Current Employment Statistics (CES) for equity payout, consumption and labor income series from 1964(Q2) to 2010(Q1). Equity payouts are the sum of net dividends of nonfarm, nonfinancial and farm business (FFA codes FA106121075 and Z1/OTHER/FA136121073), minus the total of net increase in corporate nonfinancial business and proprietors net investment of nonfinancial business (FFA codes FA103164103 and FA112090205). Consumption is defined as real personal consumption expenditures (NIPA Table 1.1.6). GDP is the measure of output and is the total of real gross domestic product, from U.S. Department of Commerce: Bureau of Economic Analysis. Labor income is defined as wages times working hours, which is real hourly compensation in the business sector (from BLS) multiplied by total private aggregate weekly hours (CES, national survey). Capital expenditures in nonfinancial business from FFA Table F.101, line 4 are the measure for investment. Debt is the total liabilities in nonfinancial business (FA144190005). All series are in billions of dollars and seasonally adjusted. Equity payouts, consumption and GDP are deflated by business value added from NIPA (Table 1.3.5). Wages, capital expenditures and debt are deflated by the price index for business value added from NIPA (Table 1.3.4). 
Table 3. Cross-correlations of real variables (VM model and the US economy)

\begin{tabular}{|c|c|c|c|c|c|c|c|}
\hline $\operatorname{Corr}\left(., c_{t}\right)$ & $\left(y_{t}, c_{t}\right)$ & $\left(l_{t}, \mathrm{c}_{t}\right)$ & $\left(i_{t}, c_{t}\right)$ & $\left(d_{t}, c_{t}\right)$ & $\left(b_{t}, c_{t}\right)$ & $\left(w_{t}, c_{t}\right)$ & $\left(s_{t}, c_{t}\right)$ \\
\hline$\xi=0.0$ & 0.97 & 0.93 & 0.95 & -0.72 & 0.58 & 0.80 & 0.83 \\
\hline$\xi=0.1$ & 0.96 & 0.92 & 0.93 & -0.77 & 0.62 & 0.84 & 0.87 \\
\hline$\xi=0.2$ & 0.94 & 0.89 & 0.90 & -0.81 & 0.65 & 0.87 & 0.89 \\
\hline$\xi=0.3$ & 0.92 & 0.87 & 0.86 & -0.84 & 0.69 & 0.88 & 0.90 \\
\hline$\xi=0.4$ & 0.89 & 0.83 & 0.81 & -0.83 & 0.74 & 0.87 & 0.88 \\
\hline$\xi=0.5$ & 0.85 & 0.78 & 0.75 & -0.80 & 0.79 & 0.84 & 0.84 \\
\hline$\xi=0.6$ & 0.78 & 0.70 & 0.67 & -0.74 & 0.85 & 0.77 & 0.77 \\
\hline$\xi=0.7$ & 0.70 & 0.60 & 0.56 & -0.64 & 0.91 & 0.67 & 0.67 \\
\hline$\xi=0.8$ & 0.57 & 0.45 & 0.42 & -0.50 & 0.97 & 0.53 & 0.52 \\
\hline U.S. Economy & 1.00 & 0.97 & 0.96 & -0.20 & 0.60 & 0.97 & 1.00 \\
\hline $\operatorname{Corr}\left(., d_{t}\right)$ & $\left(c_{t}, d_{t}\right)$ & $\left(y_{t}, d_{t}\right)$ & $\left(l_{t}, d_{t}\right)$ & $\left(i_{t}, d_{t}\right)$ & $\left(b_{t}, d_{t}\right)$ & $\left(w_{t}, d_{t}\right)$ & $\left(s_{t}, d_{t}\right)$ \\
\hline$\xi=0.0$ & -0.72 & -0.71 & -0.69 & -0.70 & -0.38 & -0.99 & -0.98 \\
\hline$\xi=0.1$ & -0.77 & -0.74 & -0.72 & -0.71 & -0.38 & -0.99 & -0.98 \\
\hline$\xi=0.2$ & -0.81 & -0.76 & -0.74 & -0.73 & -0.38 & -0.99 & -0.98 \\
\hline$\xi=0.3$ & -0.84 & -0.79 & -0.77 & -0.74 & -0.37 & -0.99 & -0.98 \\
\hline$\xi=0.4$ & -0.83 & -0.81 & -0.80 & -0.76 & -0.37 & -0.99 & -0.99 \\
\hline$\xi=0.5$ & -0.80 & -0.82 & -0.82 & -0.78 & -0.36 & -1.00 & -0.99 \\
\hline$\xi=0.6$ & -0.74 & -0.83 & -0.83 & -0.80 & -0.35 & -1.00 & -0.99 \\
\hline$\xi=0.7$ & -0.64 & -0.84 & -0.84 & -0.82 & -0.34 & -1.00 & -0.99 \\
\hline$\xi=0.8$ & -0.50 & -0.85 & -0.85 & -0.84 & -0.34 & -1.00 & -0.99 \\
\hline U.S. Economy & -0.20 & -0.20 & -0.22 & -0.30 & -0.40 & -0.22 & -0.21 \\
\hline $\operatorname{Corr}\left(., y_{t}\right)$ & $\left(c_{t}, y_{t}\right)$ & $\left(l_{t}, y_{t}\right)$ & $\left(i_{t}, y_{t}\right)$ & $\left(d_{t}, y_{t}\right)$ & $\left(b_{t}, y_{t}\right)$ & $\left(w_{t}, y_{t}\right)$ & $\left(s_{t}, y_{t}\right)$ \\
\hline$\xi=0.0$ & 0.97 & 0.99 & 1.00 & -0.71 & 0.37 & 0.79 & 0.84 \\
\hline$\xi=0.1$ & 0.96 & 0.99 & 1.00 & -0.74 & 0.38 & 0.81 & 0.85 \\
\hline$\xi=0.2$ & 0.94 & 0.99 & 0.99 & -0.76 & 0.39 & 0.83 & 0.87 \\
\hline$\xi=0.3$ & 0.92 & 0.99 & 0.99 & -0.79 & 0.40 & 0.85 & 0.88 \\
\hline$\xi=0.4$ & 0.89 & 0.99 & 0.99 & -0.81 & 0.41 & 0.86 & 0.89 \\
\hline$\xi=0.5$ & 0.85 & 0.99 & 0.99 & -0.82 & 0.42 & 0.87 & 0.90 \\
\hline$\xi=0.6$ & 0.78 & 0.99 & 0.99 & -0.83 & 0.44 & 0.88 & 0.90 \\
\hline$\xi=0.7$ & 0.70 & 0.99 & 0.98 & -0.84 & 0.45 & 0.89 & 0.90 \\
\hline$\xi=0.8$ & 0.57 & 0.99 & 0.99 & -0.85 & 0.44 & 0.89 & 0.90 \\
\hline U.S. Economy & 1.00 & 0.98 & 0.96 & -0.20 & 0.61 & 0.97 & 1.00 \\
\hline
\end{tabular}

The table reports the cross-correlations of output $(y)$, consumption $(c)$, labor $(l)$, investment $(i)$, dividends $(d)$, debt $(b)$, wage rate $(w)$ and salary $(s)$ of the VM model by varying the habit persistence parameter value from 0.0 (without habit) to 0.8 (high level of habit persistence). The multiplier of the HP filter is 1600 . U.S data series defined in the note to Table 2 . 
Table 4. Mean and relative standard deviation (RSD in \%) for the RA model

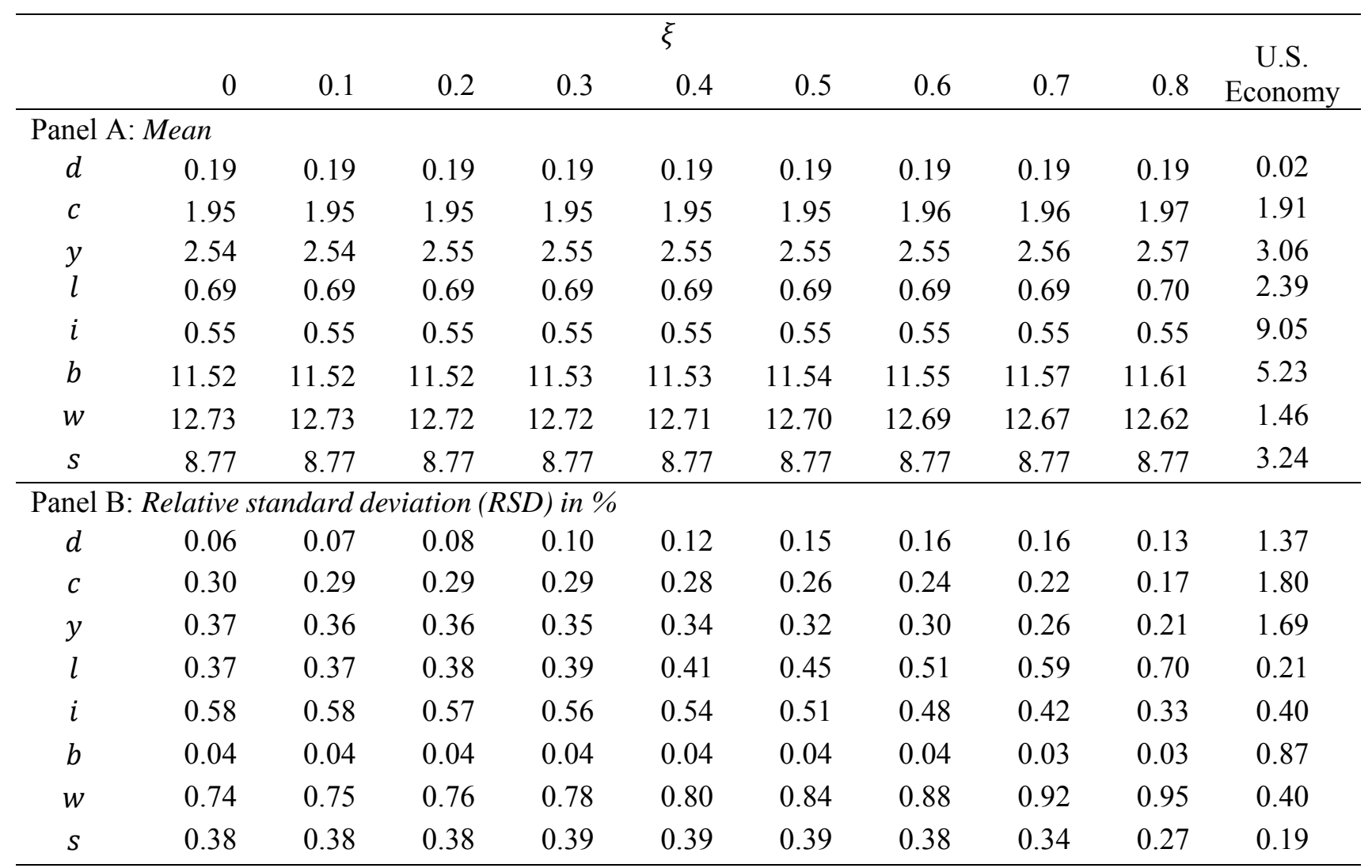

The table reports the mean and the relative standard deviations (\%) of aggregate dividends $(d)$, consumption (c), labor $(l)$, output $(y)$, capital $(k)$, investment $(i)$, debt $(d)$, wages rate $(w)$ and salary $(s)$, generated from the risk-averse model. $\xi$ is persistence of habit in consumption. The extended equilibrium model is incorporated with aggregate dividend policy and with different values of habit persistence. All data are detrended by Hodrick and Prescott filter (HP filter). The multiplier of the HP filter is 1600 . U.S data series defined in the note to Table 2. 
Table 5. Cross-correlations of real variables (RA model)

\begin{tabular}{|c|c|c|c|c|c|c|c|}
\hline $\operatorname{Corr}\left(., c_{t}\right)$ & $\left(y_{t}, c_{t}\right)$ & $\left(l_{t}, \mathrm{c}_{t}\right)$ & $\left(i_{t}, c_{t}\right)$ & $\left(d_{t}, c_{t}\right)$ & $\left(b_{t}, c_{t}\right)$ & $\left(w_{t}, c_{t}\right)$ & $\left(s_{t}, c_{t}\right)$ \\
\hline$\xi=0.0$ & 1.00 & -1.00 & 1.00 & 0.20 & -0.01 & 1.00 & 0.98 \\
\hline$\xi=0.1$ & 1.00 & -1.00 & 1.00 & 0.12 & -0.01 & 0.99 & 0.98 \\
\hline$\xi=0.2$ & 1.00 & -1.00 & 1.00 & 0.03 & -0.01 & 0.99 & 0.97 \\
\hline$\xi=0.3$ & 1.00 & -0.98 & 1.00 & -0.05 & -0.02 & 0.97 & 0.96 \\
\hline$\xi=0.4$ & 1.00 & -0.96 & 1.00 & -0.10 & -0.02 & 0.95 & 0.94 \\
\hline$\xi=0.5$ & 1.00 & -0.91 & 1.00 & -0.13 & -0.01 & 0.91 & 0.92 \\
\hline$\xi=0.6$ & 1.00 & -0.82 & 1.00 & -0.13 & -0.01 & 0.86 & 0.90 \\
\hline$\xi=0.7$ & 1.00 & -0.71 & 1.00 & -0.12 & 0.00 & 0.78 & 0.88 \\
\hline$\xi=0.8$ & 1.00 & -0.58 & 1.00 & -0.10 & 0.01 & 0.67 & 0.87 \\
\hline U.S. Economy & 1.00 & 0.97 & 0.96 & -0.20 & 0.60 & 0.97 & 1.00 \\
\hline $\operatorname{Corr}\left(., d_{t}\right)$ & $\left(c_{t}, d_{t}\right)$ & $\left(y_{t}, d_{t}\right)$ & $\left(l_{t}, d_{t}\right)$ & $\left(i_{t}, d_{t}\right)$ & $\left(b_{t}, d_{t}\right)$ & $\left(w_{t}, d_{t}\right)$ & $\left(s_{t}, d_{t}\right)$ \\
\hline$\xi=0.0$ & 0.20 & 0.18 & -0.20 & 0.16 & 0.75 & 0.11 & 0.02 \\
\hline$\xi=0.1$ & 0.12 & 0.10 & -0.09 & 0.08 & 0.71 & 0.00 & -0.08 \\
\hline$\xi=0.2$ & 0.03 & 0.02 & 0.06 & 0.00 & 0.67 & -0.13 & -0.20 \\
\hline$\xi=0.3$ & -0.05 & -0.06 & 0.22 & -0.08 & 0.64 & -0.27 & -0.32 \\
\hline$\xi=0.4$ & -0.10 & -0.11 & 0.38 & -0.13 & 0.61 & -0.40 & -0.43 \\
\hline$\xi=0.5$ & -0.13 & -0.14 & 0.53 & -0.15 & 0.60 & -0.52 & -0.51 \\
\hline$\xi=0.6$ & -0.13 & -0.14 & 0.67 & -0.16 & 0.62 & -0.62 & -0.56 \\
\hline$\xi=0.7$ & -0.12 & -0.13 & 0.78 & -0.15 & 0.65 & -0.72 & -0.59 \\
\hline$\xi=0.8$ & -0.10 & -0.11 & 0.86 & -0.12 & 0.69 & -0.80 & -0.58 \\
\hline U.S. Economy & -0.20 & -0.20 & -0.22 & -0.30 & -0.40 & -0.22 & -0.21 \\
\hline $\operatorname{Corr}\left(., y_{t}\right)$ & $\left(c_{t}, y_{t}\right)$ & $\left(l_{t}, y_{t}\right)$ & $\left(i_{t}, y_{t}\right)$ & $\left(d_{t}, y_{t}\right)$ & $\left(b_{t}, y_{t}\right)$ & $\left(w_{t}, y_{t}\right)$ & $\left(s_{t}, y_{t}\right)$ \\
\hline$\xi=0.0$ & 1.00 & -1.00 & 1.00 & 0.18 & -0.03 & 1.00 & 0.99 \\
\hline$\xi=0.1$ & 1.00 & -1.00 & 1.00 & 0.10 & -0.03 & 0.99 & 0.98 \\
\hline$\xi=0.2$ & 1.00 & -1.00 & 1.00 & 0.02 & -0.03 & 0.99 & 0.98 \\
\hline$\xi=0.3$ & 1.00 & -0.99 & 1.00 & -0.06 & -0.03 & 0.98 & 0.96 \\
\hline$\xi=0.4$ & 1.00 & -0.96 & 1.00 & -0.11 & -0.03 & 0.95 & 0.95 \\
\hline$\xi=0.5$ & 1.00 & -0.91 & 1.00 & -0.14 & -0.03 & 0.92 & 0.92 \\
\hline$\xi=0.6$ & 1.00 & -0.83 & 1.00 & -0.14 & -0.03 & 0.96 & 0.90 \\
\hline$\xi=0.7$ & 1.00 & -0.72 & 1.00 & -0.13 & -0.02 & 0.79 & 0.88 \\
\hline$\xi=0.8$ & 1.00 & -0.59 & 1.00 & -0.11 & -0.01 & 0.68 & 0.87 \\
\hline U.S. Economy & 1.00 & 0.98 & 0.96 & -0.20 & 0.61 & 0.97 & 1.00 \\
\hline
\end{tabular}

The table reports the cross-correlations of output $(y)$, consumption $(c)$, labor $(l)$, investment $(i)$, dividends $(d)$, debt $(b)$, wage rate $(w)$ and salary $(s)$ of the RA model by varying the habit persistence parameter value from 0.0 (without habit) to 0.8 (high level of habit persistence). The multiplier of the HP filter is 1600 . U.S data series defined in the note to Table 2 . 